
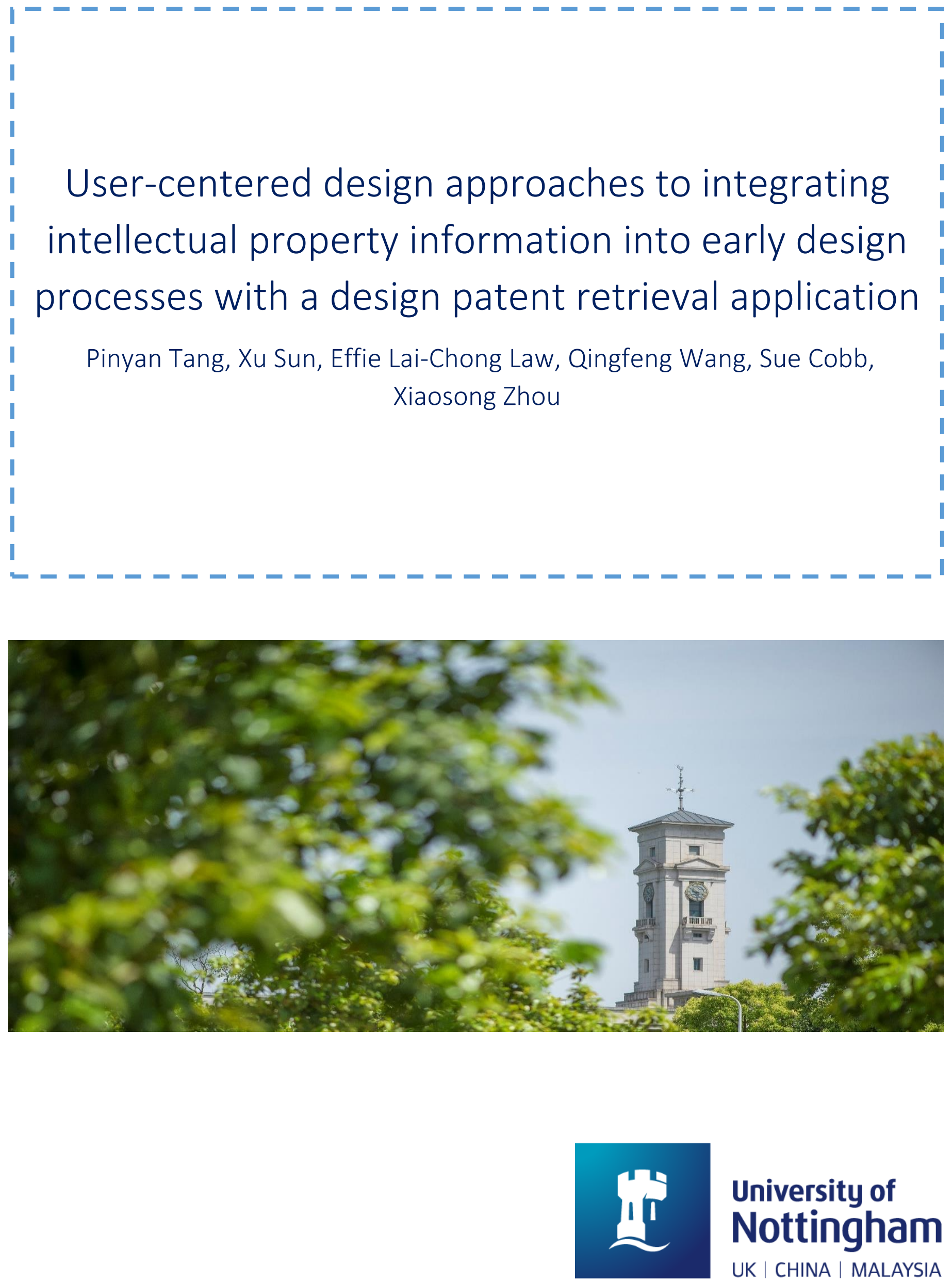

University of Nottingham 
University of Nottingham Ningbo China, 199 Taikang East Road, Ningbo, 315100, Zhejiang, China.

First published 2019

This work is made available under the terms of the Creative Commons Attribution 4.0 International License:

http://creativecommons.org/licenses/by/4.0

The work is licenced to the University of Nottingham Ningbo China under the Global University Publication Licence:

https://www.nottingham.edu.cn/en/library/documents/researchsupport/global-university-publications-licence.pdf 


\title{
User-Centred Design Approaches to Integrating Intellectual Property Information into Early Design Processes with a Design Patent Retrieval Application
}

Pinyan Tang ${ }^{\text {ad }}$, Xu Sun ${ }^{\text {ad }}$, Effie Lai-Chong Law ${ }^{\mathrm{b}}$, Qingfeng Wang ${ }^{\mathrm{c}}$, Sue Cobb ${ }^{\mathrm{d}}$, Xiaosong Zhou e

${ }^{a}$ Department of Mechanical, Materials and Manufacturing Engineering, University of Nottingham, Ningbo, China

${ }^{b}$ Department of Informatics, University of Leicester, U.K.

${ }^{c}$ Nottingham University Business School China, University of Nottingham, Ningbo, China

${ }^{\mathrm{d}}$ Human Factors Research Group, Faculty of Engineering, University of Nottingham, U.K.

${ }^{\text {e }}$ School of Mechanical and Electrical Engineering, Guizhou Normal University, China

Key words: user-centred design; creative design processes; intellectual property; patent retrieval; industrial design

\begin{abstract}
The relationship between intellectual property rights (IPRs) and the development of creativity is always a controversial topic. However, it has seldom been explored from the user-centred design (UCD) perspective. This paper describes how the UCD approach has been employed to develop Design Patent Retrieval Application (acronym: DsPLAi), a mobile app aimed to integrate IPRs related information into early design processes to enhance designers' IP practice and to facilitate the creative process. Interview studies were first conducted to identify end-users' understanding of IPRs and related practices. Next, participatory design workshops with designers and IP processionals were organised to understand the interaction between the two parties and their needs, thereby deriving requirements for DsPLAi. A prototype of the app was developed and evaluated with ten industrial designers. The prototype received positive feedback in the usability evaluation. The empirical results showed that the provision of IPRs related information at an early stage could be helpful to the design process and that the designers were positive about the use of DsPLAi in their daily design routines.
\end{abstract}




\section{Introduction}

What is intellectual property (IP)? IP is defined as non-physical property whose value is based upon an idea or ideas (Hughes, 1988). IP rights (IPRs) provide an exclusive right to market an invention for a fixed time (Gallini \& Scotchmer, 2002). There are different regimes in IPRs, such as copyright, trademarks, utility patents, and design patents (the categories vary slightly with different countries). The IPRs regimes are supposed to incentivize creativity and benefit society as a whole after its impetus begins in supporting individual inventors (Merges, 2011, p. 71; Robinson, 2016). Instead of examining the role of IPRs in the society or creative industries from a macroscopic perspective, this research focused on its influence on individual inventors or designers. At the individual level, inventors of a design idea, which is the core element of an IP regime, play a critical role in IPRs. Inventors or designers are the beneficiaries of IPRs protection, as their interests are protected through the IPRs by excluding others from using the features of their designs (Mckenna \& Strandburg, 2014). On the other hand, they are also constrained by IPRs, especially when protected information is needed for further creation (Fishman, 2015). Related research has been conducted on individual inventors or designers from the perspective of artists' labour markets, most of which focused on individual creators' motivation for creating, and how an IPRs regime incentivizes inventors or designers in their creativity (Towse, 2010). However, very few empirical studies have attempted to understand the role of IPRs in terms of how and why designers "do what they do" and "whether or how the law [of IP] has a role in their activities" (Silbey, 2011, p. 2093). To address these problems, the UserCentred Design (UCD) approaches were applied in this research to investigate the relationship between IPRs and the development of creativity from the perspective of individual designers.

Specifically, this research focused on the IPR regime of design patents, which was established to protect the values in design that trademarks, copyright, and utility patents failed to protect (Lee \& Sunder, 2013). According to the Manual of Patent Examining Procedure 1502 (9th ed. rev. 2015), in the context of a design patent, the design is defined as "an article [which] consists of the visual characteristics embodied in or applied to an article". The subject of a design patent focuses on the visual appearance of a product, rather than its function. In the history of IP development, design patents are deemed a controversial domain. There have been arguments that the patent system is rooted in its underdeveloped theoretical foundations, and has been claimed 
to be a failure(Lee \& Sunder, 2013; Nguyen, 2010). However, such a situation has been changing significantly in the last decade. The value of design has been increasingly recognized, which leads to the rising status of design patents as mechanisms for "capturing and monetizing" such benefit (John et al., 2013; Lee and Sunder, 2013, p. 278). Vassallo (2017) described how design "has become as indispensable as technology", and this trend will continue to grow, which implies a promising future development of the domain of design patent.

With design patent being the focus of this research, the term "designer" in this paper refers to industrial designers whose primary responsibility is developing the visual parts of products. This research fills the knowledge gap by looking closely into individual industrial designers' design processes and examining the potential role of IPRs related information herein. Specifically, this paper presents our work on developing an app for retrieving design patents based on the needs and requirements of end-users, which in this case are individual designers, to integrate IPRs related information into design processes. People tend to believe that an IPRs regime would constrain designers' creativity by limiting their ability to use protected works (e.g., James Boyle, 2008, p. 15). However, this belief is not consistent with either the history of the arts or psychological research on the creative process (Fishman, 2015).

The overall goal of this research was twofold. First, it aimed to examine empirically the effect of providing IPRs related information in an early design stage on the creative process. Second, by developing the app, this research aimed to demonstrate how the UCD approaches could be applied to enable the integration of IPRs related information into design processes.

\section{Background and Theory}

\subsection{The current status of IP in the creative industry}

The term "creative industry" (CI) is a board concept which covers a wide range of activities such as industrial design, architecture, and advertising, and at the same time implies the necessity that a product/service contains a substantial artistic/creative element (UNESCO, 2006). Considerable research highlights the fact that CIs do not only bring direct economic values by manifesting creative goods or employment of creative professionals but also have a general role in driving and facilitating the process of change across the entire economy (Potts \& Cunningham, 2008). With creativity as the core value, the development of CIs is heavily influenced by the level of protection 
offered by IPRs. Previous studies suggest that IPRs are both an internal asset and an external force to Cis (Towse, 2010). However, there are always deficiencies of attention in protecting IPRs to various extents across different countries and regions. For European countries, a recent survey shows that the general public's understanding of IP has increased. However, such an understanding has decreased for the younger generations, and in general, the concept of IPRs is considered to be somewhat abstract by many (Berland, 2013). For developing countries such as China, it has long been regarded as the capital of counterfeiting and piracy (Cao 2014; Zimmerman \& Chaudhry 2009). Although there is an increasing number of studies identifying China's progress in this domain (Nguyen, 2012; Sepetys \& Cox, 2009), IP protection is still ranked as the primary challenge for multinational businesses operating in China (Schotter \& Teagarden, 2014). Considering the typical role of China in the domain of IP and its reference significance for countries with similar progress in IP development, the current paper specifically chose China as the location where all the data collection studies took place.

In CIs, technological and artistic creativity are two distinctive categories (Towse, 2010). Artistic creativity, because of its stereotyped image for being lack of practical value, is prone to be underestimated and overlooked even in the CIs boom. Design has nature similar to artistic works in general but is also dictated by features stemming from function, technology, and fashion, resulting in its awkward status in the IPR regime (Afori, 2008). There have been ongoing arguments of enacting a sui generis copyright law for design which, however, is deemed to be a long and essentially random process, and involving multidisciplinary inquiries into areas such as psychology, sociology, and philosophy (Afori, 2008). This paper focused on the visual part of designs, of which the main source of protection from being imitated or copied illegally is design patents in the IPRs system ${ }^{1}$. However, its application is never easy; such as the process to certify their worth is expensive and time-consuming, and the judgement whether the design meets the statutory standards is always subjective (Brown, 1987).

\subsection{Design process and IPRs protection}

Design as a noun, which refers to the thing designed, has an apparent relationship with IPRs protection, as it is the tangible medium that manifests the intangible values protected by IPRs.

\footnotetext{
${ }^{1}$ Copyright laws also protect basic forms, but they have no requirement of novelty or merit (Brown, 1987), and therefore are not covered in this paper.
} 
Design is also a verb, referring to the process of design, and its relationship with IPRs protection is not often discussed. It is undeniable that design, as one of the significant intellectual activities because of the effects its results can have on society (Gero \& Mc Neill, 1998), has its essential place in the IP regime. To understand the relationship between the two, it is necessary to understand the nature of the design process. In the history of design research, different theoretical approaches have been proposed to identify the intricacies of design. Among them, many researchers have agreed on a co-evolutional nature of problems and solutions in design (e.g. Dorst and Cross, 2001; Halstrøm and Galle, 2015). Maher and Poon (1996) proposed a model design process based on a genetic algorithm, which suggests a co-evolutional nature of the problem space and the solution space in the design process, where the two co-evolve, interchanging information along the way. The design process in their model is described as an exploration where problems interact and evolve with solutions over time ( Maher \& Poon, 1996). As mentioned earlier, IPRs protect the benefits of the designers and at the same time constrain them. To apply them into the process of design, IPRs protects the design solution space, and at the same time restrict the design problem space.

Such a double-edged relationship is more evident in the design model proposed by Ralph and Wand (2009) which reveals the detailed information of the inputs and outputs of a design process. Ralph and Wand (2009) defined design as "a specification of an object" that is formed with a set of "primitive components", and is intended to accomplish goals, but "subject to some constraints", and need to "satisfy a set of requirements" (p. 108). The specification in this definition refers to the characteristics of the structure, namely the fundamental components and their connections. They are the objects that IPRs are trying to protect. The requirements and constraints in this definition are subject to the structural and behavioural property of a design. The former refers to the quality that a design must possess regardless of environmental conditions whereas the latter refers to the required responses of a design to "a given set of environmental conditions or stimuli"

(Ralph \& Wand, 2009). IP regime is an integral part of the sociocultural environment (Menell, 2016), and therefore constitutes part of the behavioural property of a design.

\subsection{Creativity and IPRs protection}

Creativity is considered to be a mysterious aspect of design (Dorst \& Cross, 2001), and as Norn and Salvendy (2006) claimed, is sometimes deemed "non-measurable and indefinable" (p. 156). 
Researchers from different fields have been working on identifying the nature of creativity. Sternberg (2005) argued that there are multiple creativities, rather than a single entity of creativity, which are related to processes, domains, and styles. The creativity in this paper refers to creativity in design processes. Liu (2000) found that there are different levels of creativity, namely personal and social-cultural creativity, and their interaction. He proposed that creativity is related to an individual's behaviour which is subjected to social and cultural influences. Creativity can only be recognised as creativity (but not merely novelty) when information provided by the culture and society is taken into consideration by an individual (Csikszentmihalyi, 2014; Liu, 2000). Such a definition implies a relatively macroscopic relationship between creativity and IPRs protection. The sociocultural domain, of which the IP regime is a part of, is a carrier that preserves and transmits creativity to the later generations (Csikszentmihalyi, 2014).

Some research studies aimed to understand the concept of creativity from the perspective of creative cognition (e.g. Andrews \& Smith, 1996; Shalley, Zhou, \& Oldham, 2004; ROSSO, 2014). From the point of view of the regimes of IPRs, integrating IPRs related information into design processes could be an obstacle to creative thinking, as it introduces additional requirements to, and constraints on, the design solution (Fishman, 2015). The corresponding view in creative cognition is that, as many believe, an ideal creative process should be 'unstructured, open-ended, and free of external limitations', which leads to a negative view on constraints (Andrews \& Smith, 1996; Shalley, Zhou, \& Oldham, 2004; ROSSO, 2014, p. 552). However, such a conclusion about the relationship between creativity and constraints has been challenged by many scholars. For example, Rosso (2014) proposed that different types of constraints (e.g., process constraints and product constraints) may have different impacts on creativity, depending on the circumstances, and designers who know what to do with constraints and deal with them in a right balance can benefit from the constraints. With regard to IPRs as a specific type of constraint, Fishman (2015) examined the relationship between creativity and copyright and pointed out the fact that creativity "thrives best not under complete freedom, but rather under a moderate amount of restriction” (p. 1337), and constraints may be a "source of creativity" (p. 1358) rather than a hindrance.

\subsection{Existing patent retrieval systems}

Patents have become the proxies for economic, technological, and even social activities, and it is therefore not surprising to find that the number of patent retrieval applications is increasing every 
year (Shalaby \& Zadrozny, 2019). There are non-commercial patent systems issued by different countries or regions, such as the systems issued by the UK IP Office ${ }^{2}$, the United States Patent and Trademark Office ${ }^{3}$, the European Patent Office ${ }^{4}$, and the China Patent Search and Consultation Centre of SIPO ${ }^{5}$. There are also many commercial patent search systems, such as PatBase $^{6}$ and the Derwent World Patent Index (DWPI) ${ }^{7}$. Patent documents typically contain multiple data types, such as text, images, flowcharts, formulae, etc. Consequently, the relevant methods and approaches developed for text-based information retrieval cannot be transferred directly to patent retrieval (Shalaby \& Zadrozny, 2019).

In their paper reviewing patent retrieval methods and approaches, Shalaby and Zadrozny (2019) summarized five of the most widely used patent retrieval methods currently in use: the Keywordbased method, Pseudo Relevance Feedback, the Semantic-based Method, the Metadata-based Method, and the Interactive Method (for details, see Shalaby and Zadrozny, 2019, pp. 640-652).

These methods are commonly used in current patent search/classification systems. The Keyword-based method is one of the most frequently used. However, patent documents always contain graphical data in the form of figures, technical drawings, data flow diagrams, flowcharts, graphs and plots, etc., all of which are critical in specifying the objects and ideas to be patented (Bhatti, Hanbury, \& Stottinger, 2017; Vrochidis et al., 2010). An efficient patent search tool needs to maintain the function of image-based retrieval (Vrochidis et al., 2010). Some researchers, albeit small in number, have explored the idea of an image-based patent search (e.g., Bhatti et al., 2017; Mogharrebi, Choo, \& Satria, 2013; Rusiñol, de las Heras, \& Terrades, 2015). Furthermore, some of the existing patent retrieval systems have already used image retrieval approaches. For example, Tiwari and Bansal (2004) developed PATSEEK, an image-based retrieval system for the US patent database. The PATSEEK search system interacts with the user through a simple interface, which, after submitting a query image, will present a set of similar images. The China design patent intelligent retrieval system $(\mathrm{CNIPA})^{8}$ is also an image-based

\footnotetext{
${ }^{2}$ https://www.gov.uk/government/organisations/intellectual-property-office

${ }^{3}$ https://www.uspto.gov/ptrc

${ }^{4}$ http:// worldwide.espacenet.com

${ }^{5}$ http://www.patent.com.cn

${ }^{6}$ https://www.patbase.com

${ }^{7}$ https://clarivate.com/products/derwent-world-patents-index

${ }^{8}$ http://disc.cnipa.gov.cn
} 
search system ( $\mathrm{Fu}, \mathrm{Cao}, \& \mathrm{Wu}, 2013)$. Its retrieval is based on elements of an image, such as shape, color, texture, etc., and it is performed directly, without the need for indexing. It matches the query image with any matched images, which can be shown together with 3D images.

Though the development of image retrieval technology has enabled the implementation of image-based patent retrieval system, the role of individual designers as end-users of such a system is scarcely considered in its development. For example, the PATSEEK (Tiwari \& Bansal, 2004) and CNIPA (Fu et al., 2013) focused only on the technical aspect. There is still a paucity of image-based retrieval system that has been developed with the UCD approaches, aiming to solve IP problems based on needs and preferences ofits end-users. This is the gap we aim to bridge with the application DsPLAi that we developed in this research.

\section{Methods}

\subsection{User-Centred Design approaches}

The methods used in this research for developing DsPLAi are based on the principles of UCD to take usability into serious account right from the early design process. UCD is a framework of processes in which user characteristics, goals, needs, and preferences are the central focus of each stage of the design process (Costa, Holder, \& MacKinnon, 2017; Robins et al., 2010). Since proposed initially by Donald Norman in the 1980s, the UCD approaches haven been widely used in industrial and interaction design (Chen, 2019; Costa et al., 2017; Grandi, Zanni, Peruzzini, Pellicciari, \& Campanella, 2019). The UCD approaches applied in this research were developed based on the ISO 9241-210:2010 for Human-centred design for interactive systems and other related literature (e.g., Costa et al., 2017; Maguire, 2001). According to the standard, UCD consists of six basic principles, i.e., understanding users, tasks and environments; involving users all the time; refining design through user-based evaluation; addressing the whole user experience; including multidisciplinary skills and views; and iterative processes. In this research, the three main stages identified by Costa et al. (2017) were adopted to develop the interactive processes, i.e., Pre-design, Design, and Final evaluation. According to Costa et al.'s (2017), the pre-design stage refers to activities of understanding user requirements and context of use; the design stage starts from design sketches and results in design ideas and prototypes; the final evaluation consists of trials to test prototypes. After the completion of such a process, a final design solution is expected. 


\subsection{Three-stage process}

Following the UCD principles, our research involved end-users throughout the whole design process of developing DsPLAi (see Figure 1).

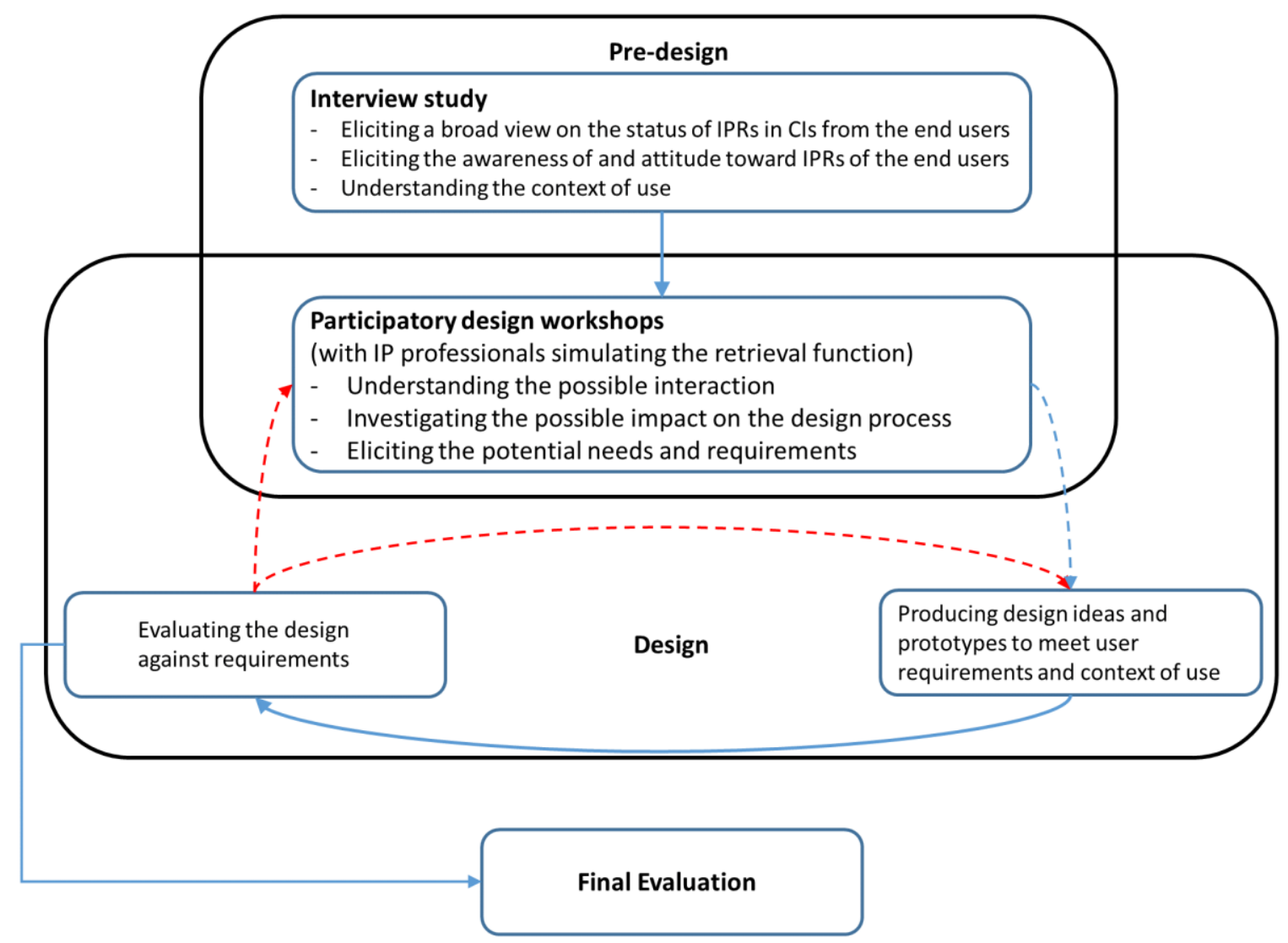

Figure 1. The UCD process applied in this research (adopted and adapted from Costa et al. (2017))

First, in the Pre-Design Phase, interviews were conducted to gather information from individual designers. It was aimed to get a broad view on the status of IPRs in the current creative industries as well as the end-users' awareness of and attitudes toward IPRs, so as to understand the role of IP in the design process and consequently the corresponding context of the use of the app to be developed. Then based on the findings of the interview study, a preliminary idea of the app design was developed and participatory workshops were conducted to test the idea. The participants of the participatory design workshops consisted of two parties, i.e., the designers and IP 
professionals ${ }^{9}-$ representing the two functioning components in the use of the app respectively the designer, and the app that carries the IPRs related information. It was 1) to understand the possible interaction between the features of the patent retrieval app and the designers; 2) to investigate the possible impact of the intervention of IPRs related information on the design process; and 3) to elicit the needs and requirements from end-users on the app DsPLAi. The participatory design workshops could be viewed as a part of the Pre-Design Phase as well as the Design Phase, which is an iterative process. Based on the corresponding findings, a prototype of the app was created based on several rounds of iterative design and evaluation against the requirements. In the Final Evaluation Phase, a heuristic evaluation study was performed to evaluate the usability of the prototype and to examine the expected impact on the design process.

\section{Pre-Design Phase}

To get an overview on the situation of awareness of and attitudes toward IPRs and the current situation of the IP regimes over China, a qualitative contextual interview study was carried out with product designers from five different cities across China, including Xi'an, Taiyuan, Tianjin, Shanghai, and Guangzhou. It is generally known that China has a vast geographic size, which inevitably produces enormous contrasts in natural and artificial conditions between different regions (Buckley, Clegg, Wang, \& Cross, 2002). The five cities were chosen to balance the potential influence of regional differences in people's awareness of and attitudes toward IPRs. The interview was semi-structured, with questions developed based on a literature review, which includes mainly three aspects: 1) awareness of IPRs, 2) current IP practice, and 3) attitudes toward IPRs 10. In general, the interviews started with the topic of the designers' daily work routine to break the ice as well as to understand the motivations of their design activities, then the researcher would guide the designers to talk about their understanding of the concept of IP, and their awareness of current IPR policies and current IPR situations. Following the understanding of their

\footnotetext{
${ }^{9}$ IP professionals in this research refer to advisors who work as an agency to provide services including patent application, trademark registration, domestic and foreign patent search, and infringement litigation, etc. They are well-equipped with IP related knowledge and normally have rich experience in patent retrieval using certain accesses. It is close to the role of IP attorney in most of the EU countries (refer to https://iprhelpdesk.eu/sites/default/files/documents/EU-IPR-Guide-IP-professionals.pdf)

${ }^{10}$ Detailed information of the interview study can be found in another article published by the same project (refer to Understanding Attitudes towards Intellectual Property from the Perspective of Design Professionals. Accepted for publication in Electronic Commerce Research). This paper only reports the part of product designers. The interview protocol can be found in Appendix 1.
} 
knowledge of IPRs, the designers were asked about the relationship between such awareness and understanding and the related practice. Specifically, the IP attitudes were evaluated by some further detailed questions.

\subsection{Participants}

The recruitment criteria mainly considered the working experience (at least one year's experience) to ensure that they had sufficient exposure to IPRs related issues. The participant recruitment process was supported by several industrial design associations in China. Altogether 39 product designers were recruited, with an average working experience of 7.3 years $(\mathrm{SD}=5.4$ years).

\subsection{Procedure}

Before the interview, each participant was briefed about the research project, the purpose, and the background of the study. The interviews took place in the working places of the participants. The working context allowed them to be immersed in the environment where they normally worked and interacted with their colleagues, and helped to elicit insights into the topics of interest. Each interview lasted for approximately 30 minutes. The interviews were audio-recorded and notes were taken.

\subsection{Results and discussion}

All interview records were transcribed into text in Nvivo 11. An Emergent Themes Analysis (e.g., Braun \& Clarke, 2006; Sun, May, \& Wang, 2016) was conducted to understand the data. In the data analysis, the first step was to find a structure, a means of setting up the different interviews for the analysis; the second step was to remove any non-essential data from the texts; the third step was to code and categorise the data according to themes. Based on the finding of product designers, three main themes were identified, namely: Motivation in design, Awareness and attitudes towards IPRs, and IP protection in design. Each theme is elaborated in the following.

\section{Motivation in design}

The literature review suggested that IP rights comprise both economic and moral rights, offering a combination of external and intrinsic reward and motivation (Towse, 2010). Two types of external motivation were identified in the interviews. Firstly, working in a design company, 
designers have to design products that can satisfy customers' requirements and the demands of the market. Secondly, designers who work under the supervision of their superiors tend to consider their work as finishing the tasks assigned by their superiors. On the other hand, the interviews revealed that, compared to external motivations, the designers showed a higher inclination toward intrinsic motivations, which include solving problems in everyday life through design, exploring ideas, or simply enjoying the process of design activity. Rather than only working for external motivations, the designers found the intrinsic motivations played a more prominent role in urging them in design practice.

\section{Awareness of and attitudes toward IPRs}

The interviews revealed problems concerning the awareness of and attitudes toward IPRs among the Chinese designers. First of all, about half of the designers mentioned the unsatisfactory IP environment and the weak enforcement of IPRs legislation in China; these issues are reflected in the ease of plagiarism and inconsequential penalties, and the low cost of plagiarism. Meanwhile, the ignorance of IPRs relevant information found in almost half of the designers interviewed, especially in relation to the applicable laws and policies, shows the low level of awareness of IPRs among the Chinese designers. An interesting finding here is that the levels of awareness of IPRs vary with the status of the designers in their organization. Designers who are in management positions tend to possess a higher level of IPRs awareness; whereas for designers in lower positions, the corresponding awareness is much lower.

\section{IP practices in design}

With regard to practice related to IP issues, some typical phenomena among the designers were identified. One phenomenon was that some of the designers showed no intention to seek any legal protection for their designs. Failure to seek protection for their designs was mainly attributed to their motivation (e.g. lacking a sense of ownership for their designs) and low levels of IPR awareness, rather than having a distrust of the IP legal system or doubts about the effectiveness of IPR law enforcement in China. Another typical phenomenon among the designers was that, though they acknowledged the importance of protecting their designs, they were not well-informed about how their designs should be protected. As a result, such designers tended to use their own methods to protect their designs. For example, they avoided uploading their designs to the Internet, 
encrypted their documented design schemes with a password to prevent unauthorized accesses, and kept their design ideas to themselves. Also, a few of the designers had registered patents or copyrights to protect their work. As some of these designers pointed out, they were reluctant to pursue this option because of the relatively high cost of a patent, both in terms of time and value of money. Some of the designers mentioned that the design firms they worked for encouraged employees to apply for patents and would pay the application fee, but very few design firms followed suit.

\subsection{User needs to be identified}

The findings of the interviews showed a general picture of the end-users' views and practice on the IPR regimes. The low level of awareness of IPRs related information and the unsatisfactory IP environment was found to be significant hindering factors for the designers to adopt appropriate IPRs related behaviours. On the other hand, the designers tended to value creativity as intrinsic reward, which was regarded as the dominant motivation for their design activities. These findings helped us identidy certain user needs that are relevant to the design of DsPLAi. For example, the use of DsPLAi should be easy and not time-consuming, which would make the access to IPR related information and the acceptance of IP relevant ideas more efficient, to help to create a more positive IP environment among the designers.

\section{Pre-Design + Design Phase}

Based on the findings of the interviews, a follow-up study in the form of a participatory design workshop was conducted, which was aimed at exploring how the provision of IPRs related information would affect the design process of individual designers, particularly from the perspective of IPRs related practice and the creative processes.

\subsection{Participants}

Five pairs of participants were recruited in the city of Ningbo to take part in collaborative design tasks, with each pair consisting of a product designer ( 2 males and 3 females) who worked on consumable products design, and an IP professional (4 males and 1 female) who, as an expert in patent retrieval, would be able to give IPRs relevant suggestions. Designers were recruited from 
design institutions and IP professionals were recruited from IP agencies. The demographic data are shown in Table 1.

Table 1. Participants'demographics for the first participatory design workshop

\begin{tabular}{ccccccc}
\hline $\begin{array}{c}\text { Group } \\
\text { No. }\end{array}$ & Gender & $\begin{array}{c}\text { Designers' } \\
\text { Age } \\
\text { range }\end{array}$ & $\begin{array}{c}\text { work } \\
\text { experience }\end{array}$ & Gender & age range & $\begin{array}{c}\text { Work } \\
\text { experience }\end{array}$ \\
\hline 1 & $\mathrm{f}$ & $26-35$ & 5 & $\mathrm{~m}$ & $26-35$ & 4 \\
\hline 2 & $\mathrm{f}$ & under 25 & 1 & $\mathrm{f}$ & $26-35$ & 4 \\
\hline 3 & $\mathrm{~m}$ & under 25 & 3 & $\mathrm{~m}$ & $36-45$ & 3 \\
\hline 4 & $\mathrm{~m}$ & under 25 & 2 & $\mathrm{~m}$ & $36-45$ & 10 \\
\hline 5 & $\mathrm{f}$ & $26-35$ & 2 & $\mathrm{~m}$ & $26-35$ & 3 \\
\hline
\end{tabular}

\subsection{Experimental design and method}

The workshop consisted of two parts - a collaborative design task and a follow-up interview. The method of focus group was applied to explore the questions of what people think, how they think, why they think that way and in particular the way they interact with each other in the context of collaborative design with IP concerns (Kitzinger, 1995). The design task was set in a given scenario in which the designer received a task to design a drinking cup for children aged 3-4 years. Considering the limited availability of the participants, the task was intended to be accomplished within 30 minutes (If the participants were willing to work longer, it was allowed. The longest workshop lasted for about 47 minutes). The designer needed to ensure that the final design would be new and would not infringe any existing design patents. An IP professional was assigned to assist the designer finishing the task.

Both the designer and the IP professional were given a laptop with the Internet connectivity. The designer was asked to finish the design task according to his/her usual design routine and was permitted to ask for any IPRs related information from the IP professional at any time. The IP professional was asked to conduct a patent information search according to the designer's requests, and to ensure the final design would not infringe any existing patents. The IP professional could choose any patent database he/she preferred or used to (different databases were used by the five 
IP professionals, including Soopat ${ }^{11}$, CNIPR $^{12}$, Rainpat ${ }^{13}$ ). Both the designer and the IP professional were encouraged to think aloud throughout the design task. After the design task, the designer and the IP professional were interviewed about their performance in the task and about their collaboration, and also any relevant comparisons with their regular design routines. The whole process was video-recorded. Their searches on the laptop were recorded by the screen capture software, Camtasia 9.

\subsection{Data analysis and results}

The process of the design task was accomplished through the collaboration of the two parties. To visualize the patterns in the design process, the model of exploration developed by Maher and Poon (1996) was adopted and adapted to present the progress of the task. An example of one of the graphs of the task processes is shown in Figure 2.

- ideas: design problems and solutions were captured as ideas, which were derived from the transcripts of the designers' think-aloud verbalisations;

- sketches: they were design artifacts produced by the designers;

- searches: the process of exploration was represented as searches involving the use of keywords for online searches, where one icon stands for one keyword used (see the triangle icons in Figure 2);

- discussions: the dialogues between the designers and the IP professionals were categorised into four themes: (i) IP-protection, which stands for the conversation on IP relevant information, such as IP policies, IP news, etc; (ii) Search-strategy, which stands for discussions on the strategy to be employed in the relevant patent retrieval, most of which are about the keywords to use; (iii) Search-result, which stands for the discussion of the results found by the IP professional; and (iv) Design-idea, which represents the conversation on the design ideas worked on by the designer.

The inter-rater reliability (IRR) agreement was computed by involving another researcher with an HCI research background, who coded the data independently, based on the four themes. A Cohen's

\footnotetext{
${ }^{11} \mathrm{http}: / /$ www2.soopat.com/Home/IIndex

12 http://search.cnipr.com/

13 https://www.rainpat.com
} 
kappa of 0.59 was obtained, indicating a moderate level of IRR. Several observable relationships between the actions were labeled in the graph (Figure 2) with the use of arrows, including a discussion which had directly inspired a design idea expressed by the designer, an idea directly inspired by a search result, and a search arising directly from a discussion.

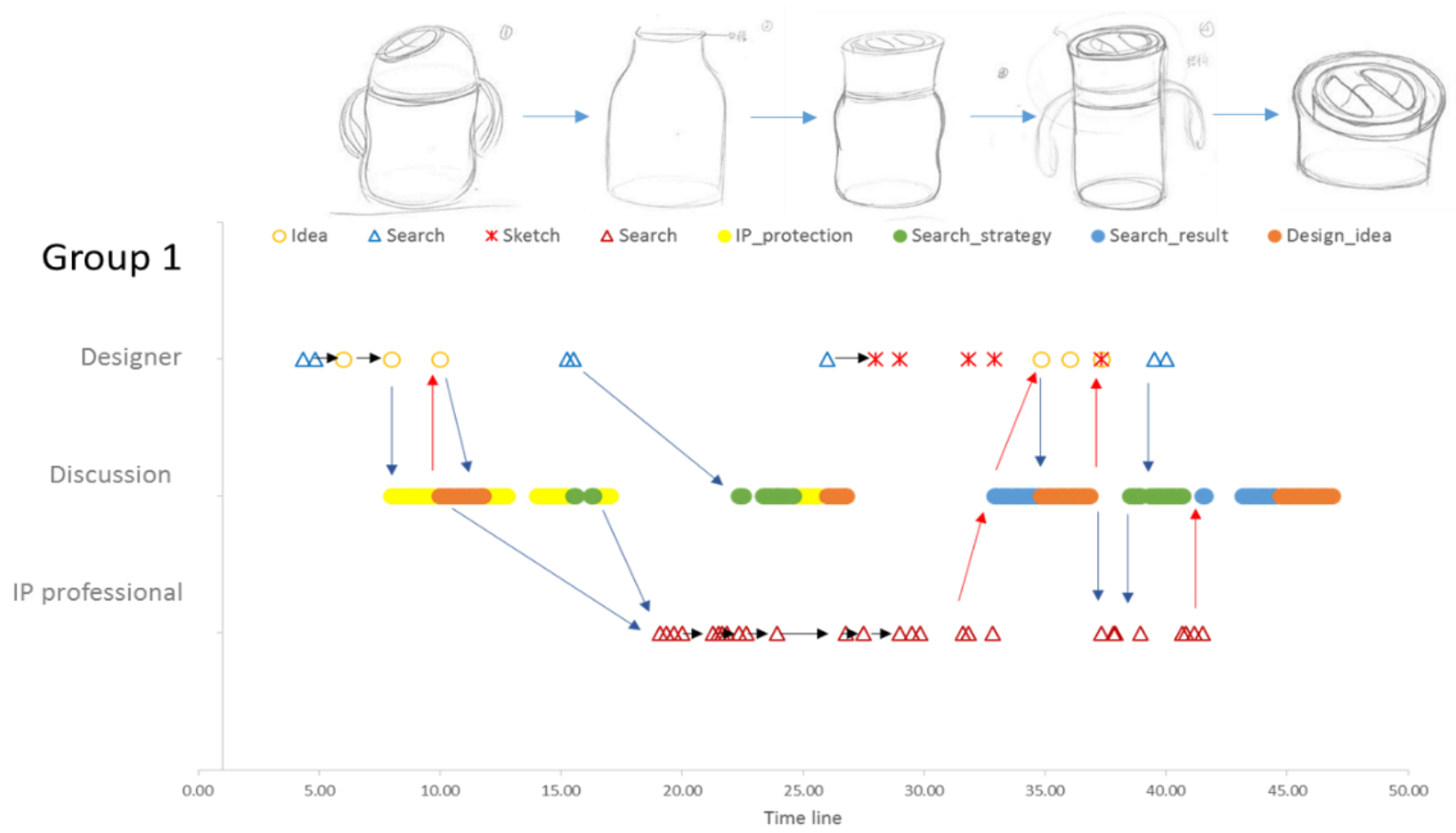

Figure 2. Process of the design task of Group 1

With respect to the outcomes, each of the five pairs of participants finished the task and came up with a final design solution. There were different levels of interaction between each pair, which varied according to many factors, such as the work experience of the designers and the IP professionals, the different patent retrieval tools they used, including Patentstar ${ }^{14}$, Soopat ${ }^{15}$, and Zhihuiya ${ }^{16}$, and the different styles of collaboration between each pair (e.g., some designers tended to offer the keywords directly to IP professionals, whereas other designers tended to discuss with the IP professionals about the potential keywords).

\footnotetext{
${ }^{14}$ https://www.patentstar.cn

${ }^{15}$ https:// www.soopat.com

${ }^{16}$ https://www.zhihuiya.com
} 


\subsubsection{An example of the task process}

Figure 2 illustrates the way the task unfolded and how the interaction progressed in Group 1, which can be interpreted as follows (see the appendices for the graphs of the other four groups):

$(0-10)$ ' The designer began an online search, which inspired her with some design ideas. She then showed these ideas to the IP professional and enquired about issues of IP protection, which led to some discussion on the design idea. In return, this discussion inspired yet another design idea, which also led to further discussions.

(11-20') The designer and IP professional continued their discussion on IP-protection related issues and the potential keywords for a patent search. Meanwhile, the designer was doing her own relevant searches. Then the IP professional began his patent search based on their discussions.

(21-30') The IP professional continued his search by trying out different combinations of keywords. The designer's search led to some new discussions on the search strategies for the patent (such as how to phrase the keywords, etc.), on the relevant IP concerns and also on some new design ideas. The designer began to sketch some design ideas for the bottle.

(30-40') The IP professional reported his search results to the designer, which inspired the designer to develop some new design ideas that were focused on the design of the bottle lid. They discussed possibles ways of designing the lid that may not violate any existing patents, after which the designer made a sketch for the lid design and the IP professional continued the relevant patent search. The IP professional concluded that the design might not violate any patents according to his research.

(41-47') The designer and the IP professional continued to check by searching to see if the final design idea violated any existing patents. They discussed the possible ways of searching for the relevant patent (such as searching the name of a brand that may have similar designs). They compared the final design idea with a number of found patents. 


\subsubsection{An example of the evolvement of design ideas based on the IPR related information}

The design ideas were found to envolve under the influence of the information from the IP designers. In some cases, the relation between the evolvement of design ideas and the IPR related information were not observable as they were not manifested in the sketches, such as shown in the data of Group 1. Figure 3 shows the interactive process of Group 3, of which the influence of IPRs related information on the design ideas is more observable in the sketches compared to that of Group 1.

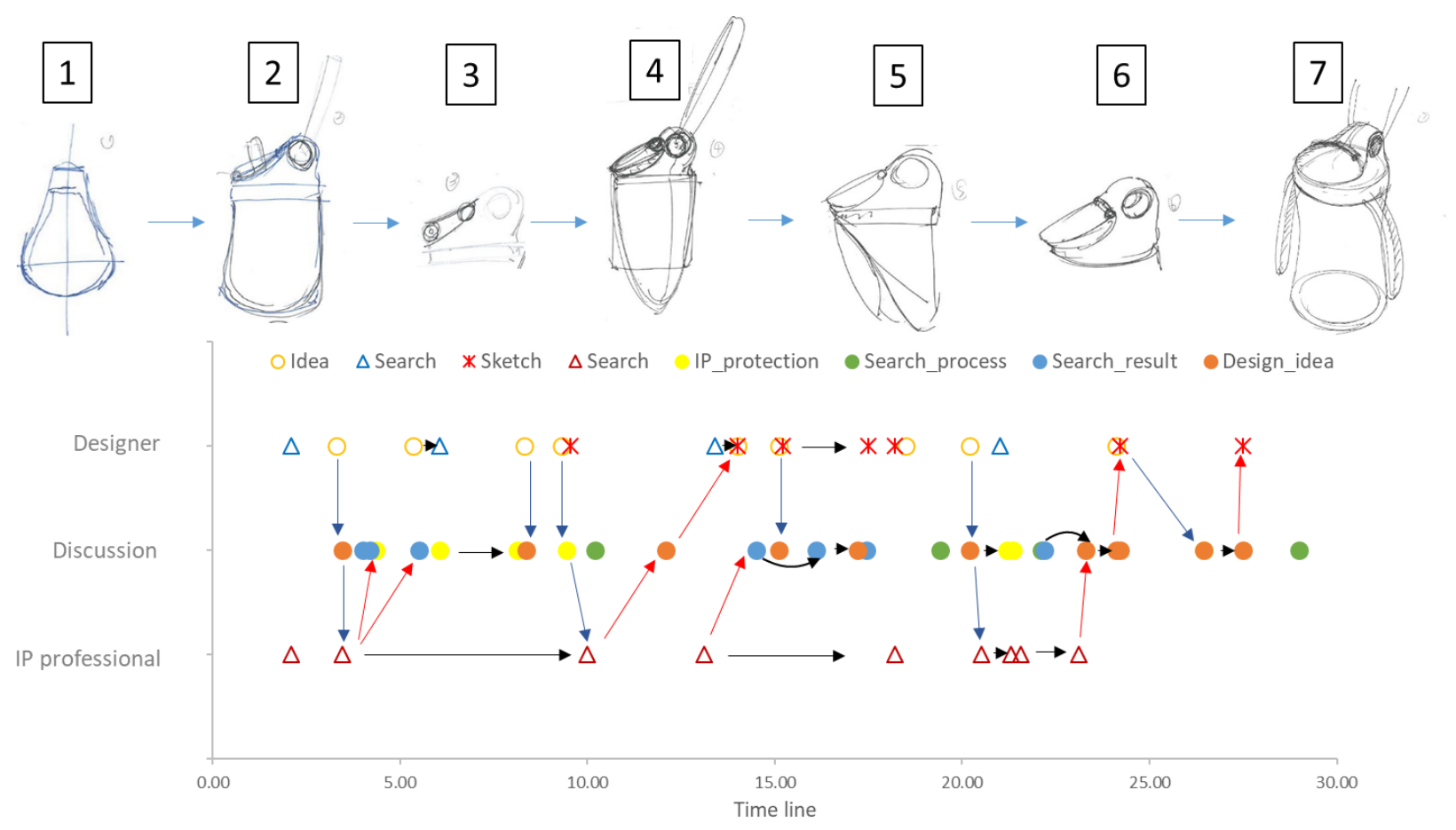

Figure 3. Process of the design task of Group 3

(0-10') The designer started with a brief idea of designing an anti-knocking-over drinking cup and explained the idea to the IP professional. The IP professional then began the search and found some relevant information (i.e. the design of a cup with the function of automatic covering the opening mouth when a knocking-over is detected). The designer was thinking of some idea of designing the cup bottom as a "tumbler" (sketch 1).

(10-20') The IP professional continued his search based on the new added keyword "tumbler" and found some similar design. He suggested some methods to avoid the possible IP infringement of the "tumbler" design, e.g., replacing the semicircle structure 
into shapes with different radian. Based on the suggestions, the designer sketched the idea of a cup with a bottom as a "tumbler" (sketch 2) with radian that is smoother than a semicircle and a specific cup lid with a hole for a lanyard (sketch 3) as an alternative way of solving the problem of knocking-over. He continued to try different bottom shapes in sketched 4 and 5 with a similar lid design.

(20-30') The designer decided to use some cartoon images of birds in the cup body and asked the IP professional about the possible IP issues. The IP professional did the relevant search and replied that there were already lots of similar designs using images of birds, and suggested that it could be a solution to use more abstract shapes instead of some realistic images. The designer then tried to integrate the shape of a duckbill with the lid design (sketch 6). Two handles were added to the bottle of the final design (sketch 7).

\subsubsection{Interaction patterns}

The task processes of each group showed some patterns that would be relevant to understanding the possible mechanism of providing IPRs related information at an early design stage.

Firstly, the processes showed that to finish the task, by coming up with a new design idea that would not infringe any existing design patents, the designers sought help from the IP professionals from the very beginning of the design process, and this would continue throughout the whole process. The collaboration usually began from the point when the designer thought of their first design idea and when the designer asked the IP professional to check the potential patents of this specific idea. During the collaboration, if the IP professional was successful in finding some information that was relevant to the designer's ideas, this information would usually be used directly for generating design ideas. At the end of the process, the designer would check any IP concerns on the final design solution with the IP professional.

In the graph, the row headed 'Designer' shows how the designer developed the whole process of their design, among which the labels of idea and sketch indicate specifically the process of how the designer navigated between any design problems and solutions. As shown in Figure 2, for Group 1, some of the ideas came from the search done by the designer, some were inspired by the discussion, and some may have come from nowhere (or were not captured by sketching or thinking aloud). For this group, the discussions between the designer and the IP professionals were found 
to have positive influences on the design process on three (traceable) occasions (of which two were triggered by the patent search results from the IP professional), as they were a direct source of inspiration for the conceptualization of design ideas or sketches. Such interactions were also found in the other four groups. The results indicate that the provision of IPRs related information at an early stage could be helpful to the design process.

\subsubsection{Feedback from the participants}

\section{About the collaboration}

For most of the participants, this kind of collaborative task was a new experience, as in their usual design routine, they would have much more time to work on the design. However, the designers had quite positive comments on the collaboration. For example, Designer 1 commented that for her regular design routine, she would have to search for the relevant information by herself, so help from the IP professional at the very beginning of the design stage saved her time and also made her more confident that her design would not violate any existing patents. Some designers commented that the collaboration was good but could be improved in specific ways such as giving longer time as it took a lot of time to communicate (Designer 2), or improving the efficiency of the feedback from IP professionals to improve the overall efficiency of such collaboration (Designer 3).

Some designers also found that the information provided by IP professionals was informative and could facilitate their design. For example:

"His information made me clearer about which part of my design needed to be redesigned because the description of the patent information is quite detailed. For example, it says that these two parts are assembled together, with what kind of materials, etc., thus, it helped me avoid the existing designs. " (Designer 2)

"I think the provided information helped me a lot. Things such as the material used, the design of the cup handle, and many other innovative points... They inspired me greatly. It is like that at the beginning, my ideas are very limited, and with Mr Chen's help, they have been greatly extended." (Designer 5) 
The most common comment from the IP professionals is that the time was quite short to undertake such a task. For example, IP Professional 2 and 3 said that in such a short time, only very rough suggestions could be made to the designer about any IP concerns. Some participants also offered suggestions to ensure collaboration in such a short time. For example:

"I think to ensure a successful collaboration, the designer needs to provide us an accurate description of her design. Probably the description should cover two aspects, such as what are the main new and innovative parts of the design, and how will you realize it... Such descriptions may help a lot in the patent searching." (IP professional 1)

\section{Does the IP information constrain the creative process?}

There were two different opinions on this topic. Two designers agreed that the information provided might restrict the creative process. Designer 1 said that if her ideas were infringing existing designers' IP, it would inevitably influence her design process. Designer 2 said she had to narrow down the scale of her sources of inspiration with the provided IP information. However, both designers also agreed that the patent information had helped them during the design process in the sense of avoiding potential IPR violation. The remaining three designers tended to think that the provided information would not necessarily hinder the design process. For example:

"I think it is natural that designing is carried out under certain constraints. Otherwise it would not be considered as creative. For example, if it normally takes 2000 dollars to produce a computer, and then some designer comes up with some brilliant idea which makes the overall cost down to 200 dollars, this is creative... and this is design for me. You have to work under different limitations..." (Designer 4)

"I don't think it is a constraint. It may restrain some part of your idea, but it also opens up other parts for you..." (Designer 3)

\section{About the current patent retrieval system}

The IP professionals were also asked to comment on the retrieval systems with which they had been working. One commonly mentioned problem with the existing systems relates to the search methods, especially when used on a design patent (exterior patent). IP Professional 1 said that a picture-based search would work better on an exterior patent, compared to a keyword-based search 
which would usually be used for invention patents. IP Professionals 3, 4, and 5 also commented on the keyword-based search method used in the existing systems. They complained that a keyword-based search could be challenging when searching for international patent databases. For example, it is quite common for them to search in the United States Patent and Trademark Office and the European Patent Office, and they are required to do a considerable amount of work to find appropriate keywords for their searches.

\subsection{Identification of user needs for DsPLAi}

The findings of the workshops suggested some potential user needs for DsPLAi. First, from the feedback of the designers, it was found that DsPLAi was expected to be used at an early design stage because in such a way it would influence the design direction to avoid possible IPR violation and save time and efforts. Also, with DsPLAi providing detailed information on relevant designs, it would help the designers to expand their design thinking for more possibilities. Another important requirement was identified from the collaboration between the designers and IP professionals. When the communication was merely depending on words, the whole process would be time-consuming and inefficient, especially when it was dealing with some design attributes. Therefore, a more efficient way of searching was expected in DsPLAi. It should be easily adopted at an early design stage and would not take up much time or interrupt the normal design process.

\section{Design Phase: Iterative Design and Evaluation}

\subsection{Preliminary design considerations of DsPLAi}

Based on the main findings and the identified user needs from the interviews and the workshops, three main attributes of the patent retrieval app were identified as follows:

- To be used at an early stage in the design

As mentioned in Section 2.2, design processes always develop with the co-evolution of problem space and solution space. The early stage of design is always flexible and capable of being planned, optimised and verified (Chueng-Nainby, 2010, p. 27). To use DsPLAi at an early design stage would be helpful for the designers to accept IP relevant ideas and follow a more appropriate IP practice routine. Furthermore, it would save the designers from spending time designing in the 
wrong direction (i.e. existing designs), and meanwhile, offer them valuable information for reference to explore more potential directions.

- To be imaged-based

According to Cross (1999), sketching assists problem structuring through solution attempts, and it promotes the recognition of new features and properties of the solution concepts. It has long been considered an essential part of the design process, and it is also the main method designers employ to communicate their design ideas (Menezes \& Lawson, 2006), especially at an early design stage when the designer is working on defining the design problems. Thus, using sketches as query images is an efficient way to match the early-stage design thinking with existing designs in a patent database. It solves patent retrieval from two perspectives: first, according to the nature of design, certain attributes, such as specific shapes, lines, etc., are not easily conveyed in words, especially in the early design stage when a design idea is usually relatively unclear. Using sketches as query images saves the transition from ideas to words. Furthermore, when the target data are existing designs from a database of design patents in an image format, it is more efficient for them to be retrieved by image to obtain a higher degree of matching.

\section{- To have high mobility}

The app needs to have high mobility, to enable use on mobile phones or tablets. This is mainly based on a consideration of ease of use. In an early design stage, a designer is required to define the design problem from different perspectives and test various possible solutions. As a result, the app should not take much time or effort and should be easy to use with any sketches produced by designers. This is also compatible with the nature of creativity, which always occurs as a sudden piece of inspiration and needs to be captured immediately by the designer (Dorst \& Cross, 2001); mobility is thus vital for the proposed app to keep the whole process consistent and thereby not interrupt the potential emergence of creative ideas.

\subsection{Initial evaluation of the preliminary design idea}

Some simple interfaces of the mobile app were developed based on the considerations above and used as a paper-based prototype to present the design idea (Figure 4), i.e., an image-based mobile design patent retrieval app used in early design stages. The designers and IP professionals who 
participated in the workshops were contacted and interviewed briefly about their comments on the design idea. Almost all of the participants gave highly positive comments on it.

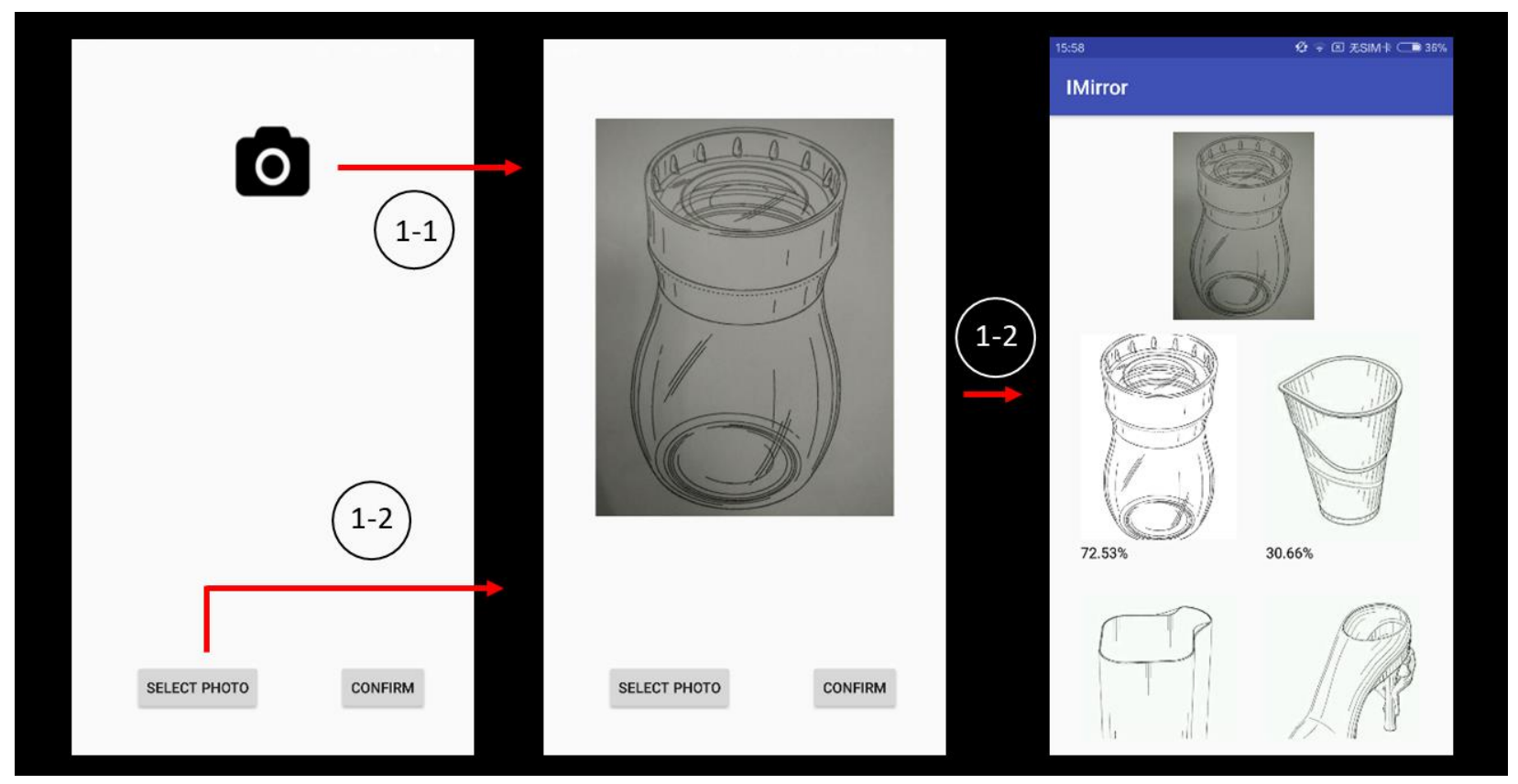

Note: Step 1: use the camera (1-1) to take a picture of the sketch, or select a photo (1-2) of a sketch from the gallery of the mobile phone. Step 2: with the picture in Step 1 as a query image, the search process is activated. The app shows the matched images from the database and the corresponding similarity percentages.

Figure 4. Paper-based prototype to present the preliminary design idea The designers commented that such an app would help a lot in their design routines, and also expressed some relevant concerns:

"I think this could be a good app. If the database is big enough, I think it will definitely help our design process... and even if it is a paid app, we would consider buying it at a reasonable price." (Designer 1)

"Yes, I think it can bring help to my work. Maybe during my design process, I won't use this app, but when I've finished my sketch, I can use this app to check whether my design has infringed any other existing patents." (Designer 2)

"If the functions can be realized, I think it could offer much help to designers." (Designer 3) IP professionals also gave very positive comments on the design idea, and even some concerns: 
"I think it is also good for us (IP professionals). Our daily work mainly consists of two parts: 1) to avoid IP infringement, and 2) to ensure whether a patent is expired. Actually, both parts require similarity comparisons, and for exterior patent search, what we always do now is to type in the name into the system, and then check the results one by one. If such an app can be realized, it can save much time for us." (IP Professional 3)

"I also think it can be beneficial to our work. But I'm a bit concerned about whether this app can meet the functional requirements. (It needs a lot of work to realise all the functions...)" (IP Professional 1)

"I think this app is more helpful to some easy designs, such as cups, tables. For complexed products, for example, I've searched a dart patent with over 100 different parts. In such a case, I think this app would not be able to cope. "(IP Professional 5)

The concerns on the design idea elicited from the participants were mainly on the technical aspect: 1) about the database, if it is big enough, and correspondingly 2) if the database is big enough, how would the search efficiency be, i.e., if it would be fast enough, and how would the matching accuracy be. Overall, all the participants gave positive comments on such a design idea and showed a strong intention to use it if it would be realized.

\subsection{Prototype development of the mobile Design Patents Retrieval App DsPLAi}

Based on the preliminary design idea above, a prototype for DsPLAi has been developed (Figure 5). The overall design philosophy was to make the interface as simple and easy as possible, only with the elements that apply the essential functions. The original version (Figure 4) followed such philosophy quite well. Some small modifications were made according to the feedback from testing, such as the position of the camera was moved to the bottom side to make it easy for onehanded performance. A 'setting' function was added for the setting of the arrangement of the matching results (e.g., from the highest similarity to the lowest similarity and vice versa).

DsPLAi was developed to be deployed by designers to search for existing patent information, using their sketches as the search key. It works in the following way: When the designer produces a sketch, s/he can use DsPLAi to take a photograph of the same, and the system will use the photograph as the query image and will retrieve the most similar images from the patent database. 
The retrieval results will show the most similar patents, with information including the similarity percentage, the name, and description of the patents, the authors, the authorised date, etc., to help the designer to conduct any further searches (see Figure 5). Theoretically, according to the coevolutional nature of design process (Dorst \& Cross, 2001; Maher \& Poon, 1996), DsPLAi is expected to help elicit IP relevant concerns when the designer is defining the design problem, and triggering IP relevant practice when the designer is developing design solutions; and this process continues iteratively until the end of the design task. A simple, easy to use UI was developed, as shown in the screen captures (Figure 5).

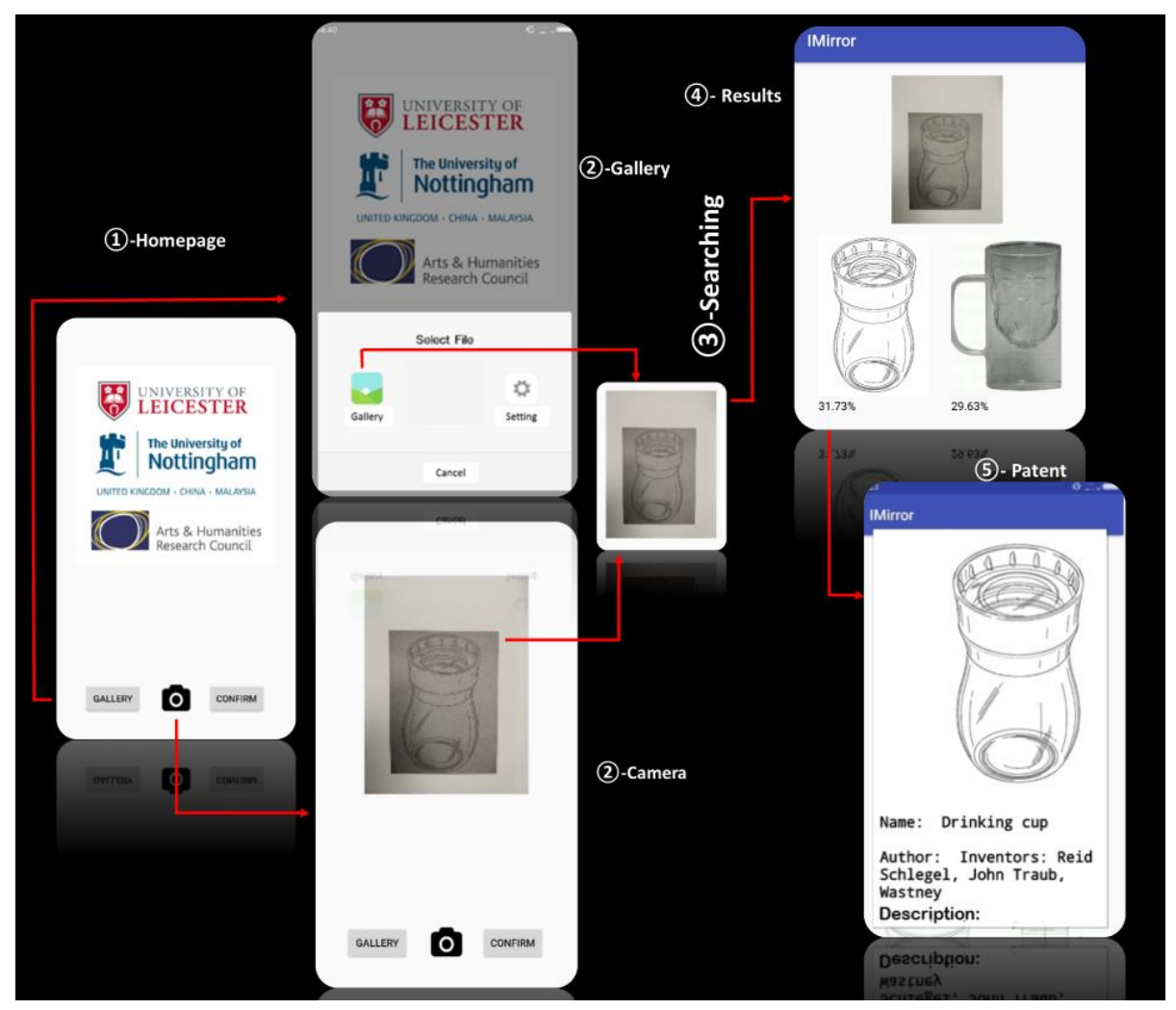

Note (1) Homepage of DsPLAi with logos and Three functional buttons at the bottom: Gallery: for storing images; Camera: for taking digital images; Cancel; (2) Depending the option clicked, a user may select a pre-stored sketch from Gallery or take a snapshot of a sketch with the digital camera. The image retrieved/recorded serves as a search key; (3) With the query image ready, the search process is activated; (4) DsPLAi returns the search results in terms of matched images from the database and corresponding similarity percentages; (5) Clicking one of the matched images, the related patent information is presented, including its name, description, author/inventor, authorized date, etc.

Figure 5. User Interfaces and workflow of DsPLAi. 
The prototype described in this paper had two main attributes: 1 . The prototype was written in the JAVA programming language based on the Android operating system, and run on mobile devices; 2. Using the established image-based searching method Histogram Comparison (OpenCV Development Team, 2017), it was intended to be used on photographs of sketches that have been developed in the early design stages, or on sketches downloaded from the Internet.

\section{Evaluation Phase: Usability evaluation of DsPLAi}

This stage was to evaluate the use of DsPLAi in real design processes. To realise the use of DsPLAi, a mini-database of one hundred and forty patent images was developed as the source images for the patent retrieval used in the study. The one hundred and forty images were randomly collected from $\mathrm{USPTO}^{17}$ to present part of the existing patents. It was not to realise some great match between existing patents and any applied sketches but to demonstrate to the participants the promised functions of DsPLAi to a high degree of similarity.

\subsection{Participants}

Ten industrial designers with work experience were recruited from local design industries to participate in the usability evaluation. The demographic information is shown in Table 2.

\subsection{Evaluation theory and methods}

The usability evaluation was based on task analysis and was followed with a heuristic design evaluation using the usability heuristics from Nielsen (2013). The task analysis was used to test the presupposed functionality of DsPLAi in affecting the progress of the design process, particularly from the perspective of IPRs related practice and the creative processes. It was to test if the use of DsPLAi at an early design stage may help the designers follow a more appropriate design routine that would not infringe existing IPRs; also, it was to test if the provision of IPRs related information may constrain the creative process. From the perspective of usability, it was to identify if the features of DsPLAi matched user preferences and met user requirements; or if there were any constraints on the effectiveness, efficiency, and satisfaction in the context of use (Wickens, Lee, Liu, \& Gordon-Becker, 2014).

\footnotetext{
${ }^{17}$ http://www.uspto.gov/
} 
Table 2 Participants' demographics in the usability evaluation study of DsPLAi

\begin{tabular}{ccccc} 
& $\begin{array}{c}\text { Participant } \\
\text { No. }\end{array}$ & Gender & Age & Work experience (years) \\
\hline \multirow{4}{*}{ Group } & P1 & M & $26-35$ & 6 \\
$\mathbf{1}$ & P2 & M & $26-35$ & 10 \\
& P3 & M & $26-35$ & 3 \\
& P4 & F & $26-35$ & 5 \\
& P5 & M & Under 25 & 1 \\
\hline \multirow{2}{*}{ Group } & P6 & M & $26-35$ & 4 \\
$\mathbf{2}$ & P7 & M & Under 25 & 1 \\
& P8 & M & Under 25 & 1 \\
& P9 & F & Under 25 & 1.5 \\
& P10 & F & $26-35$ & 3 \\
\hline
\end{tabular}

\subsection{Experimental design}

The usability evaluation was designed to be completed in 1.5 hours and consisted of two parts. In the first part, the designer was asked to complete three small design tasks, with each task lasting 20 to 25 minutes. They could use a laptop with an Internet connection for information searches. The three tasks were similar and featured a milk bottle for 3-4-year-old children to be used in a kindergarten, a coffee cup for a 20-40-year-old female designer to use in her office, and a drinking bottle for a 20-40-year-old male programmer to be used in a gym. Only the task of the coffee cup design was intended to use DsPLAi, where the designers were asked to make use of the app to ensure their final design would not violate any existing patents. For the other two tasks, they were only asked to complete them on time, without any specific requests. The designers were divided into two groups (as shown in Table 2) and were asked to perform the design tasks in a different order, so as to identify any learning effects on their performance. Group 1 performed the tasks in the order of milk bottle, gym bottle, and coffee cup; whereas Group 2 performed the tasks in the order of milk bottle, coffee cup, and gym bottle. The first task for each group to design a milk bottle was intended as a trial to ensure the designers were familiar with the procedure. One hundred 
and forty pictures of cup patents captured from the United States Patent and Trademark Office were used as the database. All the pictures were transferred into the desired histogram to facilitate the method of Histogram Comparison.

The second part was a short interview to elicit the designers' evaluations of their performance as well as the usability of the app (see the questionnaire in Appendix 2 and 3). They were asked to use a 7-point scale to evaluate their performance on each task from the perspective of creativity (e.g., "how do you evaluate the originality of the final design?", where 1 = lowest in originality, 7 $=$ highest in originality). The criteria used to evaluate the creativity of the final design were adopted from the three dimensions of Christensen and Ball's (2016) model, namely, originality, functionality, and aesthetics. Christensen and Ball's (2016) research focused on design practice evaluation. They believed that evaluative types differ in terms of the underlying evaluation logic. The three chosen dimensions (i.e., originality, functionality, and aesthetics) are sufficient to be used to predict differential behaviour for the designers because each of them was associated with a specific underpinning 'logic' that "determined the distinctive ways in which these dimensions were seen to be evaluated in practice" (p. 1). Based on their theories, evaluation of originality relates to the analysis of the history and development of concepts, functional evaluation relates to a testable objective physical reality of concepts, and aesthetic evaluation is subject to temporal shifts in appreciation and rests on the affective and cognitive dimensions in perceiving the objects. Such connotations were introduced to the designers to help them evaluate subjectively their own performance on creativity.

Besides, they were asked to evaluate their corresponding IP practice in each task from the perspectives of IPRs related considerations, IPRs related activities, and the possibility of infringing design patents in their final designs.

They were also asked to evaluate the usability of DsPLAi, in terms of assessing the visibility, consistency, flexibility, and efficiency of use. Elements of the questions were adapted from Nielsen's (2013) usability heuristics. In addition, a statement was included to provide an overall evaluation of the user experience, and they were asked to indicate whether DsPLAi had been helpful for their design routine and whether they planned to use it for any future work. Finally, they were requested to leave further feedback on the design of DsPLAi. 
The design processes were video-recorded, and the designers were asked to think-aloud during the design processes to enable the capture of their thought processes. Searches on the laptop were recorded with the screen capture software.

To gain a more objective evaluation of the designers' performance in creativity, the method of expert review was also employed. Three design experts (one design manager and two design lecturers) were recruited to evaluate the final designs on the three aforementioned dimensions of creativity.

\subsection{Data analysis and results}

The ten recruited designers completed the three given design tasks within the set time. In total, 30 independent tasks were performed and 30 pieces of final designs were collected.

\subsubsection{Effect of DsPLAi on the design process}

The same method of visualising the design process used in the participatory design workshops (in section 5.3) was used to map the design processes. The ideas, which were either expressed via thinking-aloud or written down on paper, the sketches on paper, the online search processes, and the use of the app, were presented on a timeline (see Figure 6 as an example).

The ideas in the graph, either presented as a sketch or idea talked, stand for a unit of the process of "problem to solution" as shown in Figure 6. The way the app was used in this process was as follows: at around 14', the designer used the DsPLAi, which led to a design idea presented as a sketch at 16'; at 19', the designer checked an idea (talked) using DsPLAi, and then came up with another idea (talked). Although the use of DsPLAi was for a relatively short time, the process shown in Figure 6 proves that it had a positive influence on the development of the designer's creative ideas. 


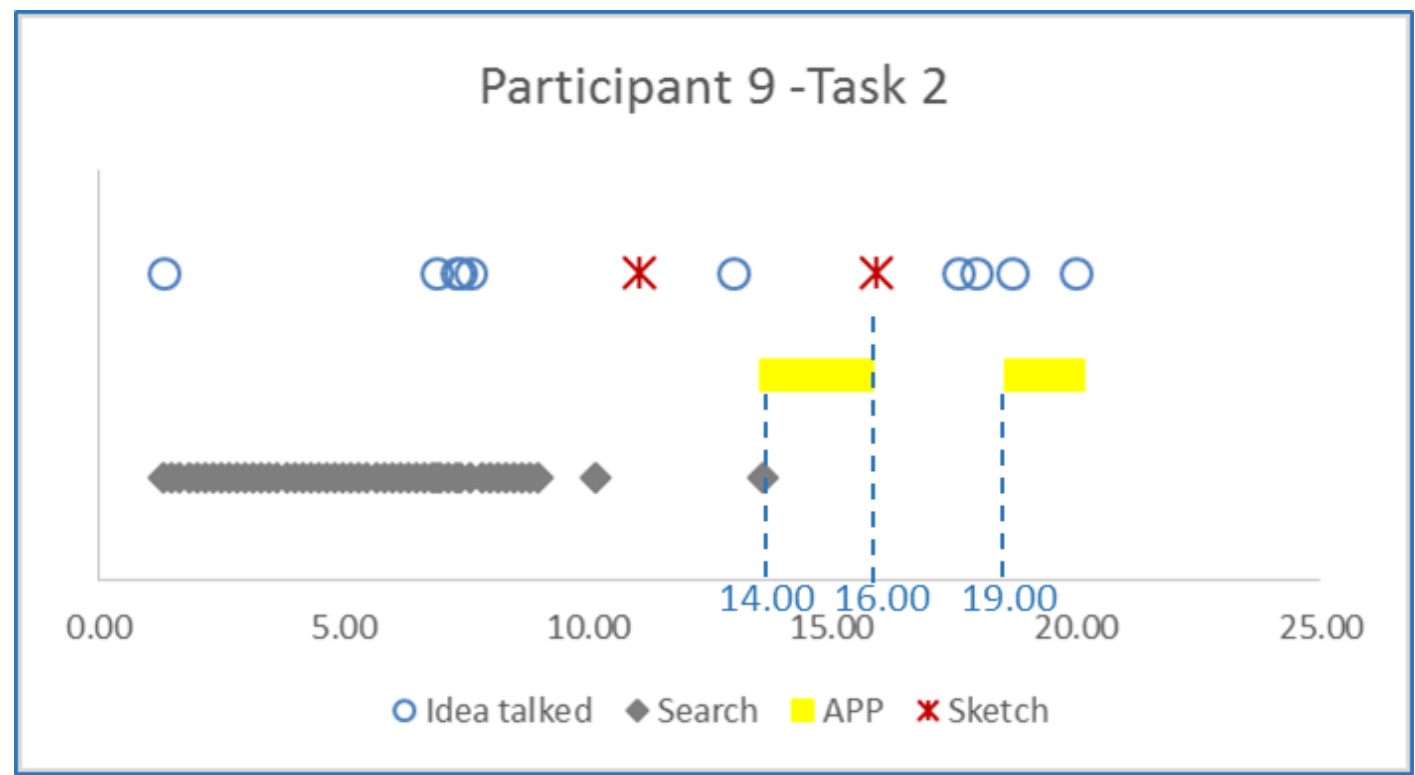

Figure 6. The design process of Participant 9 on Task 2 (with the use of DsPLAi)

\subsubsection{Effect of DsPLAi on creativity in the final designs}

- The number of ideas talked aloud and sketches

The numbers of ideas talked aloud (IT) and sketches (S) of each participant are presented in Table 3.

To further understand the effect of using DsPLAi on the designers' performance in terms of creativity in general, Friedman tests were conducted to determine whether there were differences in the number of ideas talked aloud or sketches during the three tasks for both groups. For Group 1, the number of ideas talked aloud for Task $3(\mathrm{Mdn}=20)$ was slightly higher than that of Task 1 $(\operatorname{Mdn}=17)$ and Task $2(\operatorname{Mdn}=12)$, but the differences were not statistically significant $\left(\chi^{2}(2)=\right.$ $1.368, \mathrm{p}=.504)$. Similarly, the number of sketches for Task $3(\mathrm{Mdn}=11)$ was slightly higher than that of Task $1(\mathrm{Mdn}=9)$ and Task $2(\operatorname{Mdn}=5)$, but the differences were also not statistically significant $\left(\chi^{2}(2)=1.368, \mathrm{p}=.504\right)$.

The results for Group 2 were slightly different from those of Group 1. The number of ideas talked aloud for Task $2(\mathrm{Mdn}=10)$ was slightly smaller than that of Task $1(\mathrm{Mdn}=13)$ and Task $3(\mathrm{Mdn}$ $=23$ ), but the differences were not statistically significant $\left(\chi^{2}(2)=.737, p=.692\right)$. Similar results were found in the number of sketches, where Task $2(\mathrm{Mdn}=3)$ was slightly smaller than for Task 
$1(\mathrm{Mdn}=6)$ and Task $3(\mathrm{Mdn}=4)$, but, again, the differences were not statistically significant $\left(\chi^{2}(2)=4.526, p=.104\right)$. The results indicate that the use of DsPLAi did not have a significant influence on the creative process in terms of the number of ideas and sketches.

Table 3. Numbers of ideas from Group 1 and Group 2

\begin{tabular}{lcccccccccc} 
Group 1 & \multicolumn{2}{c}{ P1 } & \multicolumn{2}{c}{ P2 } & \multicolumn{2}{c}{ P3 } & \multicolumn{2}{c}{ P4 } & \multicolumn{2}{c}{ P5 } \\
\hline & IT & S & IT & S & IT & S & IT & S & IT & S \\
\hline Task 1 & 33 & 15 & 7 & 7 & 3 & 9 & 17 & 1 & 20 & 10 \\
Task 2 & 20 & 4 & 11 & 13 & 17 & 15 & 6 & 2 & 12 & 5 \\
Task 3 (with & & & & & & & & & & \\
DsPLAi) & 30 & 12 & 10 & 11 & 21 & 13 & 12 & 1 & 20 & 3 \\
\hline Group 2 & \multicolumn{2}{c}{$\mathbf{P 6}$} & \multicolumn{2}{c}{$\mathbf{P 7}$} & & $\mathbf{P 8}$ & & $\mathbf{P 9}$ & \multicolumn{2}{c}{ P10 } \\
\hline & IT & $\mathbf{S}$ & $\mathbf{I T}$ & $\mathbf{S}$ & $\mathbf{I T}$ & $\mathbf{S}$ & $\mathbf{I T}$ & $\mathbf{S}$ & $\mathbf{I T}$ & S \\
\hline Task 1 & 24 & 10 & 29 & 10 & 11 & 5 & 13 & 6 & 10 & 3 \\
Task 2 (with & & & & & & & & & & \\
DsPLAi) & 46 & 18 & 29 & 6 & 10 & 2 & 10 & 2 & 4 & 3 \\
Task 3 & 35 & 9 & 28 & 5 & 7 & 4 & 23 & 3 & 5 & 2 \\
\hline
\end{tabular}

Note. $I T=$ ideas talked about,$S=$ sketches made.

- Subjective evaluation of creativity

The creativity of the final designs was rated by the designers themselves, and also by the three recruited experts. The medians of the ratings from the designers themselves and the experts are included in Table 4. Friedman tests were used to determine where there were any statistically significant differences between each dimension of creativity between the three tasks in Group 1 and Group 2, respectively. Significant differences in Group 1 were found only in the rating for originality from the designers $\left(\chi^{2}(2)=6.400, \mathrm{p}=.041\right)$, but a post hoc analysis of pair comparison did not reveal any significant differences between each pair of tasks. An overview of the results for the creativity of the final designs can be seen in the medians of the ratings from the different evaluators in Table 4. 
Table 4 Medians of ratings of creativity for Tasks 1, 2 and 3

\begin{tabular}{llcccccc}
\hline & & \multicolumn{3}{c}{ Group 1 } & \multicolumn{3}{c}{ Group 2 } \\
\cline { 3 - 8 } & Task 1 & Task 2 & $\begin{array}{c}\text { Task 3 } \\
\text { (with } \\
\text { DsPLAi) }\end{array}$ & Task 1 & $\begin{array}{c}\text { Task 2 } \\
\text { (with } \\
\text { DsPLAi) }\end{array}$ & Task 3 \\
\hline \multirow{3}{*}{ Designers } & Originality & 2 & 5 & 5 & 4 & 4 & 4 \\
& Functionality & 3 & 5 & 4 & 5 & 5 & 5 \\
& Aesthetics & 5 & 5 & 4 & 5 & 5 & 4 \\
\hline \multirow{5}{*}{ Experts } & Originality & 5 & 4 & 5 & 4 & 4 & 3 \\
& Functionality & 4 & 6 & 5 & 4 & 4 & 4 \\
& Aesthetics & 4 & 5 & 4 & 4 & 4 & 4 \\
\hline
\end{tabular}

\subsubsection{Usability and user experience of using DsPLAi}

The designers were also asked to evaluate the usability of the prototype DsPLAi. The simple design received quite positive feedback on the aspects of information presentation, words/phrases used, ease of use, feedback and the overall user experience (as shown in Table 5).

Table 5 Rating of usability of the DSPLAi prototype (Scale: $1=$ very bad, $7=$ very good)

\begin{tabular}{cccccc}
\hline & $\begin{array}{c}\text { Logical } \\
\text { information } \\
\text { presentation }\end{array}$ & $\begin{array}{c}\text { Consistent and } \\
\text { standard } \\
\text { words/phrases }\end{array}$ & Easy to use & $\begin{array}{c}\text { Reasonable } \\
\text { feedback }\end{array}$ & $\begin{array}{c}\text { Good user } \\
\text { experience }\end{array}$ \\
\hline Median & 5 & 6.5 & 6 & 5 & 5 \\
\hline
\end{tabular}

\subsubsection{Preference for DsPLAi and further feedback}

In the interviews, the median of the ratings for "the app is helpful to my design process" and "I wish to use this app in my daily design routine" were both 6 , which indicates a high preference for DsPLAi from the participants. The preference for DsPLAi was directly reflected in the data for Group 2, where Participants 6, 7, and 8 also used the app in Task 3, although they had not been asked to do so. Most of the participants expressed significant interest in DsPLAi, especially when complemented with all the promised features, such as a precise matching between the query image and the patent database, and a larger database with information of patents from different countries. 
Some specific requirements from DsPLAi were also collected from the feedback. For example, a few participants suggested that the subject of the app should not be limited to exterior patents, but should also include functionality attributes, while the searches should be based both on images and the inclusion of a keyword search as a complementary solution. Some participants also suggested that the query image should not be limited to sketches, but should also include photographs of products.

\subsubsection{IP concerns and practice during the tasks}

The participants were also asked about their concerns on IPRs and the corresponding practice during the tasks. The medians of the ratings from the designers themselves are reported in Table 6.

Table 6 Medians of ratings for IP concerns and practice for Tasks 1, 2 and 3 (Scale: $1=$ very

$$
\text { little, } 7 \text { = very much) }
$$

Group $1 \quad$ Group 2

\begin{tabular}{lcccccc}
\cline { 2 - 7 } & Task 1 & Task 2 & Task 3 & Task 1 & Task 2 & Task 3 \\
\hline IP concerns & 5 & 4 & 4 & 3 & 4 & 4 \\
IP practice & 5 & 6 & 4 & 3 & 4 & 4 \\
Possibility of no & & & & & & \\
infringement & 4 & 6 & 6 & 6 & 4 & 6 \\
\hline
\end{tabular}

Friedman tests were also applied to determine where there were any statistically significant differences between each dimension for the three tasks in Group 1 and Group 2, respectively. Significant differences were only found in the rating for Possibility of no infringement for Group $1\left(\chi^{2}(2)=6.706, p=.035\right)$, but the post hoc analysis of pair comparison did not reveal any significant differences. Some possible explanations were elicited from the interviews. Firstly, a majority of the participants stated that for a small design task of 20 minutes, they were focused more on the idea generation, rather than checking any IPRs related issues. Secondly, given that the three tasks were quite similar to each other, there were still different considerations for each design, and any concerns about IP issues may vary with the tasks rather than with the condition (i.e. with or without the use of DsPLAi). In general, the participants agreed that the use of the app had played a role in reminding them about IP concerns during the design process. 


\section{General Discussions}

\subsection{The UCD approaches and other considerations in the design of DsPLAi}

In this project, the UCD approaches were applied for the development of DsPLAi, implying the involvement of the representative end-users through the initial ideas in the Pre-Design Phase till an interactive prototype of DsPLAi for usability evaluation in the Final Evaluation Phase. Specifically, the participatory design workshops at the early design stage of this project offered valuable information in understanding the possible interaction patterns between the two working components of the app as well as the potential user needs and requirements and therefore derived the initial design prototype. An obvious benefit of the provision of IPRs related information at an early design stage is that it improves designers' IP practice in design, as it encourages them to address any relevant concerns at the beginning of a project. However, the mismatch between the IPRs regime and its target user groups, of which designers are a typical group, have been prevalent across many countries in the world since the introduction of the concept of IP (Fisher III, 1999). Only by merely offering IPRs related information to designers would not be a remedy to such a problem. Instead, it needs to be investigated from the perspective of the designers by actually considering their needs and preferences. Although there are existing patent retrieval systems, such as the online systems mentioned earlier, the majority of such systems were not designed according to the needs and requirements of the designers who make up a significant percentage of their endusers, but focused more on the perspective of technologies (e.g., Shalaby \& Zadrozny, 2019; Tiwari $\&$ Bansal, 2004). The attributes of the systems are not designer-friendly, as they were not designed based on the nature of design processes. The pre-design research has revealed that to enable efficient patent retrieval at early design stages, there are two essential attributes needed to be manifested, i.e., high mobility and using sketches as query images. To the best of our knowledge, currently, there seems no mobile patent retrieval app. Many of the systems could only search by keywords, while some commercial systems which search by image will always impose strict requirements on the query images (e.g., Bhatti et al.'s, 2017, whose method is only applicable for technical drawings). DsPLAi was developed based on the needs and requirements of designers, which were identified through the UCD processes.

The feedback from the participants offered valuable information for the improvement of DsPLAi. Some participants claimed that the classification of any search results, such as by design type, 
should improve the quality of matches and searches. Also, some participants suggested that searching by elements of the design would also be helpful in the design process. For example, for the cup design, it would have been useful if it could also conduct a search by the design of the handle. Further development of DsPLAi, from the perspectives of both usability and technology, will be needed to realise these functions.

\subsection{The potential positive effects of DsPLAi on design processes}

The protection of creative ideas is critical to the development of the creative industries, which is also one of the aims of IPRs. Industrial designs, due to a "hybrid nature" of both artistic and technological creativities, are challenging to get proper treatment in the IP regimes (Afori, 2008, p. 1107). This research specifically chose the regime of design patent as a potential solution to protect the creative ideas manifested in the visual characteristics of a design. It aimed to explore a way of integrating IPRs related information into designers' early creative design processes so as to improve the corresponding IP practice; and at the same time, to facilitate their creative processes. The design theories (e.g. Maher \& Poon, 1996; Ralph \& Wand, 2009) confirmed a close relationship between IPRs protection and design processes, which offers a theoretical base for the development of DsPLAi.

From the specific perspective of Chinese designers, the results of the interviews with the designers revealed that there were relatively low awareness and negative attitudes towards IPRs, and also relatively adverse IP practice. The adverse IP practice may be attributed to a variety of reasons, among which the ignorance of IPRs related information, especially in the case of IP legislation and policies, is a non-negligible one. Nevertheless, the pre-design research also revealed that provided the undesirable IP circumstance such as unauthorised imitation and missing due recognition for re-using creative products, and the designers still tended to show passion for creating, which could be learned from their inclination to the intrinsic motivations in designing (cf. Section 4.3). This is also one of the premises for the realisation of the application DsPLAi, which can facilitate creativity in design processes. Also, we have been motivated to explore the possibility to increase IP as well as promote the creativity in design processes awareness by introducing DsPLAI. The results of the participatory design workshops with designers and IP professionals further confirmed the necessity and utility of introducing IPRs related information in the early stages of the design process. 
Although the topic of whether IPRs protection hinders or promotes creativity remains controversial, the results and feedback from the workshops have offered some empirical support that constraints, which are IPRs protection in this context, do not necessarily impede the development of creativity. This finding resembles the conclusion from Fishman (2015), who claimed that creativity thrives best under a moderate amount of restriction. Fishman (2015) also proposed that to stimulate creativity, constraints need to meet two criteria: First, they should promote variability, by helping to differentiate from existing products and designs; and second, they should promote engagement, as inventors are more likely to be inspired by rules if they derive satisfaction from following any such rules. The excludability mechanism of IPRs promotes variability, and the application of DsPLAi enables the designers to be more close to IPRs and therefore encourage more engagement. The evaluation study confirmed that the use of DsPLAi did not hinder the development of creativity in the design processes, which confirmed both the results of the workshops and Fishman's (2015) statement.

Owing to the limitation of the current research, DaPLAi was still a prototype with a limited database, and therefore no further evidence has been collected to test its fitness to the designers' current approaches and how would the designers further progress in their design process with the information from DaPLAi. For instance, would they continue to develop their ideas and use DaPLAi later for IP infringement checking? Or would they choose to use DaPLAi at the beginning of their design to look for similar products and then start from something different? Such information would be valuable for further understanding of the development of creativity in the design process. The follow-up project will aim to develop DsPLAi further and address these research questions.

\section{Conclusions and future work}

According to Archer (1979), there should be a designerly way of thinking and communicating, which is distinct from scientific and scholarly ways of thinking and communicating, but it should be as powerful and as scientific when being applied to its own kinds of problems. Although creativity in design is always deemed to be a mysterious topic (Dorst \& Cross, 2001), the continuous research on design methodologies has revealed the intricacies of design and the potential ways of improving designers' practice. The development of the human society induced the emergence of the concept of IP, which is significant in shaping the methods and the 
environments of design activities. Design is a social behaviour due to the influence of its results on society (Gero \& Mc Neill, 1998). Therefore, designers have to introduce IPRs related information into their design routines to cope with the changes in social mechanisms. Fortunately, there are also new technologies emerging to support designers in their traditional design routines, such as the development of new design tools (e.g. CAD, CASE, etc.). Also, interactive devices such as mobile phones and tablets are increasingly been used to support design activities (Magallanes, Sánchez, Cervantes, \& Wan, 2018). The concept of the patent retrieval mobile app is a viable and timely idea of equipping designers with advanced technologies, based on the investigation of the role of intellectual property in the design process. Although the research was designed and conducted in China, the methodological framework could be adapted to similar empirical work with designers from and within other cultures.

One of the main contributions of this paper is the proposed concept for the design of the app DsPLAi, which can be used by designers in the early stages of design, mainly because of its high mobility. Due to the compromises in the technology used for image search, the evaluation of the use of the app and the investigation of its relationship with the development of design processes, especially the development of creativity, could not be more extensive because of the budgetary constraint. Nonetheless, intriguing results and insights into supporting IPRs through advanced technologies could still be obtained. Our future studies will aim to improve on these issues and to realise the proposed functions utilising the ever-increasingly sophisticated machine learning methods. Besides, longitudinal studies should be designed to further understand the influence of the use of DsPLAi on designers' IP practices in real-life contexts and to test its fitness to their existing design approaches. We anticipate that with the deployment of a fully functional DsPLAi app, the awareness of, attitude towards, and practice of IP protection by designers in the creative industries could be enhanced significantly.

Furthermore, this study narrowed the scope of the research to focus only on the early stages of the design process. Nevertheless, the ideas developed for DsPLAi could be adopted in a much broader range of applications. For example, in collaborative design when designers need to communicate design ideas (Tang, Lee, \& Gero, 2011), a quick and easy method of checking the IP status of design ideas would be helpful for efficient communication between the different parties. Also, DsPLAi would be useful for IP professionals by facilitating their patent searches. It is possible that 
with further development, a commercialized DsPLAi app could play a significant role in the domain of design, as well as in the realm of intellectual property.

\section{Reference}

Afori, O. F. (2008). Reconceptualizing Property in Designs. Cardozo Arts \& Entertainment Law Journal, 25(3), 1105-1178.

Andrews, J., \& Smith, D. C. (1996). In Search of the Marketing Imagination : Factors Affecting the Creativity of Marketing Programs for Mature Products. Journal of Market Research, 33(2), 174-187.

Ang, S. H., Cheng, P. S., Lim, E. a. C., \& Tambyah, S. K. (2001). Spot the difference: consumer responses towards counterfeits. Journal of Consumer Marketing, 18(3), 219-235.

Archer, B. (1979). Whatever became of design methodology. Design Studies, Vol. 1, pp. 17-18.

Berland, E. (2013). European Citizens and Intellectual Property: Perception, Awareness and Behaviour. Office for Harmonization in The Internal Market. Alicante, Spain.

Bhatti, N., Hanbury, A., \& Stottinger, J. (2017). Contextual local primitives for binary patent image retrieval. Multimedia Tools and Applications. https://doi.org/10.1007/s11042-0174808-5

Boyle, J. (2008). The public domain: Enclosing the Commons of the Mind. New Haven, CT: Yale University Press.

Braun, V., \& Clarke, V. (2006). Using thematic analysis in psychology. Qualitative Research in Psychology, 3(May 2015), 77-101. https://doi.org/10.1191/1478088706qp063oa

Brown, R. S. J. (1987). Design Protection: An Overview. UCLA LAW REVIEW, 34(Faculty Scholarship Series. Paper 2692.), 1341-1404.

Buckley, P. J., Clegg, J., Wang, C., \& Cross, R. (2002). FDI, regional differences and economic growth: panel data and evidence from China. Transantional Corporations, II(1), 1-28.

Cao, Q. (2014). Insight into weak enforcement of intellectual property rights in China. 
Technology in Society, 38, 40-47.

Chen, Y. (2019). Exploring Design Guidelines of Using User-Centered Design in Gamification Development: A Delphi Study. International Journal of Human-Computer Interaction, 35(13), 1170-1181. https://doi.org/10.1080/10447318.2018.1514823

Christensen, B. T., \& Ball, L. J. (2016). Dimensions of creative evaluation: Distinct design and reasoning strategies for aesthetic, functional and originality judgments. Design Studies, 45(Part A), 116-136.

Chueng-Nainby, P. (2010). Conceptualisation, or not? An Ethnographic Study in Describing Early Design Collaboration between Western Designers and Chinese Designers. Thesis, $(\mathrm{PhD})$. Edinburgh Napier University.

Costa, N. A., Holder, E., \& MacKinnon, S. N. (2017). Implementing human centred design in the context of a graphical user interface redesign for ship manoeuvring. International Journal of Human-Computer Studies, 100(September 2016), 55-65. https://doi.org/10.1016/j.ijhcs.2016.12.006

Cox, A.,\& Sepetys, K.(2009). Intellectual property rights protection in China: Trends in litigation and economic damages. NERA Economic Consulting. 10.2139/ssrn.1330619.

Cross, N. (1999). Natural intelligence in design. Design Studies, 20(1), 25-39. https://doi.org/10.1016/S0142-694X(98)00026-X

Csikszentmihalyi, M. (2014). Society, Culture, and Person: A Systems View of Creativity. In The Systems Model of Creativity (pp. 47-61). Dordrecht, Netherlands: Springer. https://doi.org/10.1007/978-94-017-9085-7_4

Dorst, K., \& Cross, N. (2001). Creativity in the design process: Co-evolution of problemsolution. Design Studies, 22(5), 425-437. https://doi.org/10.1016/S0142-694X(01)00009-6

Fisher III, W. W. (1999). The Growth of Intellectual Property: A History of the Ownership of Ideas in the United States. Retrieved from https://cyber.harvard.edu/people/tfisher/iphistory.pdf 
Fishman, J. P. (2015). Creating around copyright. Harvard Law Review, 128, 1333-1404. https://doi.org/10.3366/ajicl.2011.0005

Fu, B., Cao, S., \& Wu, S. (2013). Novelty assessment of image retrieval technique-based patent outward appearance design literature. Chinese Journal of Medical Library and Information Science, 22(9), 62-64.

Gallini, N., \& Scotchmer, S. (2002). Intellectual Property: When Is It the Best Incentive System? NBER/Innovation Policy and the Economy, 2(1), 51-77. https://doi.org/10.1162/153134602753396976

Gero, J. S., \& Mc Neill, T. (1998). An approach to the analysis of design protocols. Design Studies, 19(1), 21-61. https://doi.org/10.1016/S0142-694X(97)00015-X

Grandi, F., Zanni, L., Peruzzini, M., Pellicciari, M., \& Campanella, C. E. (2019). A Transdisciplinary digital approach for tractor's human-centred design. International Journal of Computer Integrated Manufacturing. https://doi.org/10.1080/0951192X.2019.1599441

Halstrøm, P. L., \& Galle, P. (2015). Design as Co-Evolution of Problem, Solution, and Audience. Artifact, 3(4), 3. https://doi.org/10.14434/artifact.v3i4.12815

Hughes, J. (1988). The Philosophy of Intellectual Property. Georgetown Law Journal, 77, 287365.

John, J., Mont, D., \& Janis, M. D. (2013). The Origins of American Design Patent Protection. Indiana Law Journal, 88(3), 837-880.

Kitzinger, J. (1995). Qualitative Research: Introducing focus groups. British Medical Journal, 311, 299-302.

Lee, P., \& Sunder, M. (2013). Design Patents: Law Without Design. Stanford Technology Law Review, 17, 277-304.

Liu, Y.-T. (2000). Creativity or novelty? Design Studies, 21(3), 261-276. https://doi.org/10.1016/S0142-694X(99)00013-7

Magallanes, Y., Sánchez, J. A., Cervantes, O., \& Wan, W. (2018). A pattern-based approach for 
developing creativity applications supported by surface computing. International Journal of Human-Computer Studies, 110(November 2016), 134-154.

https://doi.org/10.1016/j.ijhcs.2017.10.010

Maguire, M. (2001). Methods to support human-centred design. International Journal of Human-Computer Studies, 55, 587-634. https://doi.org/10.1006/ijhc.2001.0503

Maher, M. Lou, \& Poon, J. (1996). Modelling Design Exploration as Co-Evolution. ComputerAided Civil and Infrastructure Engineering, 11(3), 195-209.

Mckenna, M. P., \& Strandburg, K. J. (2014). Progress and competition in design. Stanford Technology Law Review, 17(1), 1-53.

Menell, P. S. (2016). Property, Inellectual Property, and Social Justice: Mapping the Next Frontier. Property Rights Conference Journal, 5, 147-195.

Menezes, A., \& Lawson, B. (2006). How designers perceive sketches. Design Studies, 27(5), 571-585. https://doi.org/10.1016/j.destud.2006.02.001

Merges, R. P. (2011). Justifying intellectual property. Cambridge Massachusetts \& London, England: Harvard University Press. Harvard University Press.

Mogharrebi, M., Choo, M., \& Satria, A. (2013). Retrieval System for Patent Images. Procedia Technology, 11(ICEEI), 912-918. https://doi.org/10.1016/j.protcy.2013.12.275

Nguyen, X.-T. (2012). The China we hardly know: revealing the new China's intellectual property regime. Saint Louis University School of Law, 55, 773-810.

Nguyen, X. T. (2010). Dynamic Federalism and Patent Law Reform. Indiana Law Journal, 85(2), 449-489.

Nielsen, J. (2013). 10 Usability Heuristics for User Interface Design. Retrieved from https://www.designprinciplesftw.com/collections/10-usability-heuristics-for-user-interfacedesign

Norn, D., \& Salvendy, G. (2006). Consumer-Based Assessment of Product Creativity: A Review and Reappraisal. Human Factors and Ergonomics in Manufacturing, 16(2), 155-175. 
https://doi.org/10.1002/hfm

OpenCV Development Team. (2017). Histogram Comparison. Retrieved October 22, 2019, from https://docs.opencv.org/2.4.13.4/doc/tutorials/imgproc/histograms/histogram_comparison/hi stogram_comparison.html

Potts, J., \& Cunningham, S. (2008). Four models of the creative industries. International Journal of Cultural Policy, 14(3), 233-247. https://doi.org/10.1080/10286630802281780

Ralph, P., \& Wand, Y. (2009). A Proposal for a Formal Definition of the Design Concept. Design Requirements Workshop, LNBIP 14, 103-136. https://doi.org/10.1007/978-3-54092966-6_6

Robins, B., Ferrari, E., Dautenhahn, K., Kronreif, G., Prazak-Aram, B., Gelderblom, G. J., ... Marti, P. (2010). Human-centred design methods: Developing scenarios for robot assisted play informed by user panels and field trials. International Journal of Human-Computer Studies, 68(12), 873-898. https://doi.org/10.1016/j.ijhcs.2010.08.001

Robinson, W. K. (2016). Economic Theory, Divided Infringement, and Enforcing Interactive Patents. Florida Law Review, 67(6), 1961-2030.

Rosso, B. D. (2014). Creativity and Constraints: Exploring the Role of Constraints in the Creative Processes of Research and Development Teams. Organization Studies, 35(4), 551585. https://doi.org/10.1177/0170840613517600

Rusiñol, M., de las Heras, L. P., \& Terrades, O. R. (2015). Flowchart recognition for non-textual information retrieval in patent search. Information Retrieval, 17(5-6), 545-562. https://doi.org/10.1007/s10791-013-9234-3

Schotter, A., \& Teagarden, M. (2014). Protecting intellectual property in China. MIT Sloan Management Review, 55(4), 41-48.

Shalaby, W., \& Zadrozny, W. (2019). Patent retrieval : a literature review. Knowledge and Information Systems, 61(2), 631-660. https://doi.org/10.1007/s10115-018-1322-7

Shalley, C. E., Zhou, J., \& Oldham, G. R. (2004). The Effects of Personal and Contextual 
Characteristics on Creativity: Where Should We Go from Here? Journal of Management, 30(6), 933-958. https://doi.org/10.1016/j.jm.2004.06.007

Silbey, J. (2011). Harvesting Intellectual Property: Inspired Beginnings and "Work-MakesWork", Two Stages in the Creative Processes of Artists and Innovators. Notre Dame Law Review, 86(5), 2091-2132.

Sternberg, R. J. (2005). Creativity or creativities? International Journal of Human-Computer Studies, 63(4-5), 370-382. https://doi.org/10.1016/j.ijhcs.2005.04.003

Sun, X., May, A., \& Wang, Q. (2016). The impact of user- and system-initiated personalization on the user experience at large sports events. Applied Ergonomics, 54, 1-9. https://doi.org/10.1016/j.apergo.2015.11.001

Tang, H. H., Lee, Y. Y., \& Gero, J. S. (2011). Comparing collaborative co-located and distributed design processes in digital and traditional sketching environments: A protocol study using the function-behaviour-structure coding scheme. Design Studies, 32(1), 1-29. https://doi.org/10.1016/j.destud.2010.06.004

Tiwari, A., \& Bansal, V. (2004). PATSEEK : Content Based Image Retrieval System for Patent Database. International Conference on Electronic Business-04, 1167-1171. Beijing, China: Tsinghua University.

Towse, Ruth. (2010). Creativity , Copyright and the Creative Industries Paradigm. KYKLOS, 63(3), 461-478.

UNESCO. (2006). Understanding Creative Industries: Cultural Statistics for Public-policy Making. UNESCO, Paris.

Vassallo, S. (2017). The past, present, and future of design in Silicon Valley. Retrieved January 1, 2017, from Crunch Network website: https://techcrunch.com/2017/04/30/the-pastpresent-and-future-of-design-in-silicon-valley/

Vrochidis, S., Papadopoulos, S., Moumtzidou, A., Sidiropoulos, P., Pianta, E., \& Kompatsiaris, I. (2010). Towards content-based patent image retrieval: A framework perspective. World Patent Information, 32(2), 94-106. https://doi.org/10.1016/j.wpi.2009.05.010 
Wickens, C. D., Lee, J. D., Liu, Y., \& Gordon-Becker, S. E. (2014). Introduction to human factors engineering. Essex, England: Pearson Education Limited. https://doi.org/wickens.

Zimmerman, A., \& Chaudhry, P. E. (2009). Protecting Intellectual Property Rights: The Special Case of China. Journal of Asia-Pacific Business, 10(4), 308-325.

https://doi.org/10.1080/10599230903340262 


\section{Appendix 1}

\section{Interview protocol}

\begin{tabular}{l}
\hline Awareness of IPR \\
Describe your understanding of IPR. \\
Describe the implications of using someone else's intellectual property. \\
\hline Current IP practice \\
Provide examples of current IP practice \\
Attitude towards IPR \\
Describe your opinion of whether IPR is important for you. \\
Describe your opinion of whether weak IPR protection harms or promotes the interests of \\
companies that create the original product. \\
Describe your opinion of whether or not it is desirable for society as a whole to have strong IPR \\
protection. \\
Describe your opinion of whether copying artefacts owned by wealthy organisations is a good or \\
bad way of redistributing wealth more equitably in our society. \\
Describe your opinion of whether or not we should always act according to our moral judgment of \\
a specific situation, and also for the collective benefit of all.
\end{tabular}




\section{Appendix 2}

\section{Part 1. About Creativity}

Please rete your creativity in the tasks from the following three aspects:

1. How do you evaluate the originality of the final design: (1-lowest in originality, 7-highest in originality)?

\begin{tabular}{|l|c|c|c|c|c|c|c|}
\hline Task 1: milk bottle & $\square 1$ & $\square 2$ & $\square 3$ & $\square 4$ & $\square 5$ & $\square 6$ & $\square 7$ \\
\hline $\begin{array}{l}\text { Task 2: Coffee cup for young } \\
\text { female }\end{array}$ & $\square 1$ & $\square 2$ & $\square 3$ & $\square 4$ & $\square 5$ & $\square 6$ & $\square 7$ \\
\hline $\begin{array}{l}\text { Task 3: Gym bottle for } \\
\text { young male }\end{array}$ & $\square 1$ & $\square 2$ & $\square 3$ & $\square 4$ & $\square 5$ & $\square 6$ & $\square 7$ \\
\hline
\end{tabular}

2. How do you evaluate the functionality of the final design: (1-lowest in originality, 7-highest in originality)?

\begin{tabular}{|l|c|c|c|c|c|c|c|}
\hline Task 1: milk bottle & $\square 1$ & $\square 2$ & $\square 3$ & $\square 4$ & $\square 5$ & $\square 6$ & $\square 7$ \\
\hline $\begin{array}{l}\text { Task 2: Coffee cup for young } \\
\text { female }\end{array}$ & $\square 1$ & $\square 2$ & $\square 3$ & $\square 4$ & $\square 5$ & $\square 6$ & $\square 7$ \\
\hline $\begin{array}{l}\text { Task 3: Gym bottle for } \\
\text { young male }\end{array}$ & $\square 1$ & $\square 2$ & $\square 3$ & $\square 4$ & $\square 5$ & $\square 6$ & $\square 7$ \\
\hline
\end{tabular}

3. How do you evaluate the aesthetics of the final design: (1-lowest in originality, 7-highest in originality)?

\begin{tabular}{|l|c|c|c|c|c|c|c|}
\hline Task 1: milk bottle & $\square 1$ & $\square 2$ & $\square 3$ & $\square 4$ & $\square 5$ & $\square 6$ & $\square 7$ \\
\hline $\begin{array}{l}\text { Task 2: Coffee cup for young } \\
\text { female }\end{array}$ & $\square 1$ & $\square 2$ & $\square 3$ & $\square 4$ & $\square 5$ & $\square 6$ & $\square 7$ \\
\hline $\begin{array}{l}\text { Task 3: Gym bottle for } \\
\text { young male }\end{array}$ & $\square 1$ & $\square 2$ & $\square 3$ & $\square 4$ & $\square 5$ & $\square 6$ & $\square 7$ \\
\hline
\end{tabular}




\section{Part 2. About Intellectual Property (IP)}

Please rete your IP practice in the tasks from the following three aspects:

1. How much do you consider IP rights during your design? (1-very little, 7-very much)

\begin{tabular}{|l|c|c|c|c|c|c|c|}
\hline Task 1: milk bottle & $\square 1$ & $\square 2$ & $\square 3$ & $\square 4$ & $\square 5$ & $\square 6$ & $\square 7$ \\
\hline $\begin{array}{l}\text { Task 2: Coffee cup for } \\
\text { young female }\end{array}$ & $\square 1$ & $\square 2$ & $\square 3$ & $\square 4$ & $\square 5$ & $\square 6$ & $\square 7$ \\
\hline $\begin{array}{l}\text { Task 3: Gym bottle for } \\
\text { young male }\end{array}$ & $\square 1$ & $\square 2$ & $\square 3$ & $\square 4$ & $\square 5$ & $\square 6$ & $\square 7$ \\
\hline
\end{tabular}

2. How much of your practice during the design is related to IP concerns (e.g. searching for IP rights related information): (1-very little, 7-very much)

\begin{tabular}{|l|c|c|c|c|c|c|c|}
\hline Task 1: milk bottle & $\square 1$ & $\square 2$ & $\square 3$ & $\square 4$ & $\square 5$ & $\square 6$ & $\square 7$ \\
\hline $\begin{array}{l}\text { Task 2: Coffee cup for young } \\
\text { female }\end{array}$ & $\square 1$ & $\square 2$ & $\square 3$ & $\square 4$ & $\square 5$ & $\square 6$ & $\square 7$ \\
\hline $\begin{array}{l}\text { Task 3: Gym bottle for } \\
\text { young male }\end{array}$ & $\square 1$ & $\square 2$ & $\square 3$ & $\square 4$ & $\square 5$ & $\square 6$ & $\square 7$ \\
\hline
\end{tabular}

3. What is the possibility of your design infringing existing design patents? (1-very little, 7 -very much)

\begin{tabular}{|l|c|c|c|c|c|c|c|}
\hline Task 1: milk bottle & $\square 1$ & $\square 2$ & $\square 3$ & $\square 4$ & $\square 5$ & $\square 6$ & $\square 7$ \\
\hline $\begin{array}{l}\text { Task 2: Coffee cup for young } \\
\text { female }\end{array}$ & $\square 1$ & $\square 2$ & $\square 3$ & $\square 4$ & $\square 5$ & $\square 6$ & $\square 7$ \\
\hline $\begin{array}{l}\text { Task 3: Gym bottle for } \\
\text { young male }\end{array}$ & $\square 1$ & $\square 2$ & $\square 3$ & $\square 4$ & $\square 5$ & $\square 6$ & $\square 7$ \\
\hline
\end{tabular}




\section{Appendix 3}

\section{Part 1. Evaluation on the APP}

1. With regard to the use of this App, to what extent do you agree with the following statements: (1-very little to 7-very much)

\begin{tabular}{|l|l|l|l|l|l|l|l|}
\hline I think_ & & & & & & & \\
\hline $\begin{array}{l}\text { The information presented } \\
\text { in this App appears in a } \\
\text { natural and logical order. (1) }\end{array}$ & $\square 1$ & $\square 2$ & $\square 3$ & $\square 4$ & $\square 5$ & $\square 6$ & $\square 7$ \\
\hline $\begin{array}{l}\text { I can understand the words } \\
\text { (language, phrases, and } \\
\text { concepts) in this App. (2) }\end{array}$ & $\square 1$ & $\square 2$ & $\square 3$ & $\square 4$ & $\square 5$ & $\square 6$ & $\square 7$ \\
\hline $\begin{array}{l}\text { This App is easy to use. (3) } \\
\text { I receive feedbacks and } \\
\text { notifications from this App } \\
\text { within a reasonable time. (4) }\end{array}$ & $\square 1$ & $\square 2$ & $\square 3$ & $\square 4$ & $\square 5$ & $\square 6$ & $\square 7$ \\
\hline $\begin{array}{l}\text { This APP is helpful to my } \\
\text { design. (5) }\end{array}$ & $\square 1$ & $\square 2$ & $\square 3$ & $\square 4$ & $\square 5$ & $\square 6$ & $\square 7$ \\
\hline $\begin{array}{l}\text { I had good experience } \\
\text { during my use of this } \\
\text { APP(6) }\end{array}$ & $\square 1$ & $\square 2$ & $\square 3$ & $\square 4$ & $\square 5$ & $\square 6$ & $\square 7$ \\
\hline $\begin{array}{l}\text { I look forward to using such } \\
\text { an APP in the daily design } \\
\text { routine (7) }\end{array}$ & $\square 1$ & $\square 2$ & $\square 3$ & $\square 4$ & $\square 5$ & $\square 6$ & $\square 7$ \\
\hline
\end{tabular}




\section{Part 2. Overall feedback}

1. Do you have any further comments or suggestions on the design of the APP? (e.g., any additional functions/requirements?) 